\title{
Teoria e institucionalização dos sistemas partidários após a terceira onda de democratização
}

\author{
Scott Mainwaring \\ University of Notre Dame, Estados Unidos \\ Mariano Torcal \\ Universitat Pompeu Fabra, Espanha
}

\begin{abstract}
Resumo
Este artigo examina duas diferenças entre os sistemas partidários das democracias industriais avançadas e os de países menos desenvolvidos, particularmente em termos do nível de institucionalização. O argumento geral é que os sistemas partidários dos países menos desenvolvidos são menos institucionalizados. De modo mais específico, mostramos primeiro que a maioria das democracias e semi-democracias em países menos desenvolvidos têm uma volatilidade eleitoral muito mais alta e menos estabilidade eleitoral do que as democracias industriais avançadas. E, em segundo lugar, boa parte da literatura sobre partidos e sistemas partidários pressupõe o contexto de sistemas partidários institucionalizados com partidos fortemente enraizados na sociedade e supõe ainda que vínculos programáticos e ideológicos estão na raiz dos vínculos estáveis entre eleitores e partidos. Nos sistemas partidários da maioria das democracias e semi-democracias dos países menos desenvolvidos, os vínculos programáticos e ideológicos entre eleitores e partidos são mais fracos. Nessa mesma direção, os vínculos entre eleitores e candidatos são mais personalistas nas democracias e semidemocracias dos países menos desenvolvidos do que nas democracias industriais avançadas.
\end{abstract}

Palavras-chave: partidos políticos, sistemas partidários, democracia, institucionalização.

\begin{abstract}
This paper examines two differences between the party systems of the advanced industrial democracies and party systems of less developed countries, particularly in terms of the level of institutionalization. The overarching argument is that the party systems of less developed countries are less institutionalized. More specifically, we first show that most democracies and semi-democracies in less developed countries have much higher electoral volatility and less electoral stability than the advanced industrial democracies. Second, much of the literature on parties and party systems assumes the context of institutionalized party systems with strong party roots in society and further presupposes that programmatic or ideological linkages are at the root of the stable linkages between voters and parties. In the party systems of most democracies and semi-democracies in less developed countries, programmatic or ideological linkages between voters and parties are weaker. In this direction also, linkages between voters and candidates are more personalistic in democracies and semi-democracies of less developed countries than in the advanced industrial democracies.
\end{abstract}

Keywords: political parties, party systems, democracy, institutionalization. 
O principal argumento deste artigo é que o nível de institucionalização é uma dimensão central para compreender os sistemas partidários ${ }^{1}$. Até meados dos anos 1990, a maioria dos trabalhos sobre partidos e sistemas partidários negligenciou esse fato, dado que tinha o alto nível de institucionalização como pressuposto. Não obstante, sem examinar a institucionalização, é impossível entender características importantes dos sistemas partidários da maioria das democracias e semi-democracias pós-1978. Os eleitores, partidos e sistemas partidários na maioria dos regimes competitivos desse período são qualitativamente diferentes daqueles das democracias industriais avançadas.

Tratamos das duas primeiras dimensões da institucionalização de um sistema partidário que Mainwaring e Scully (1995) e Mainwaring (1999, p. 22-39) desenvolveram: a estabilidade da competição entre partidos e a profundidade das raízes partidárias na democracia, que mostram diferenças grandes e persistentes entre a maioria das democracias e semi-democracias pós-1978 e as democracias industriais avançadas.

Além da maior estabilidade na competição entre partidos, o enraizamento social partidário é muito mais forte na maioria das democracias industriais avançadas, comparado à maioria das democracias e semi-democracias pós-1978. Esse grau de enraizamento partidário social varia de forte a fraco e nós analisamos duas manifestações dessa força variável. Primeiro, uma quantidade considerável da literatura teórica e comparativa pressupõe que os vínculos programáticos ou ideológicos estão na raiz dos vínculos estáveis entre eleitores e partidos. Nessas teorias, os eleitores escolhem um partido ou candidato com base em suas preferências ideológicas ou programáticas. Porém, na maioria das democracias e semi-democracias pós-1978, esses vínculos são fracos e constituem uma parte fundamental do frágil enraizamento partidário na sociedade.

A outra manifestação empírica desse frágil enraizamento é que os vínculos entre eleitores e candidatos são mais personalistas na maioria dos regimes competitivos pós1978 do que nas democracias industriais avançadas. Fora destas, muitos eleitores escolhem os candidatos com base em suas características pessoais, sem levar em conta partido, ideologia ou questões programáticas. O alto grau de personalismo reflete esse enraizamento e vai contra o que se espera, tomando como base a maior parte da literatura teórica sobre eleitores e sistemas partidários. O personalismo introduz um critério importante para avaliar a institucionalização dos partidos: a despersonalização dos partidos e da competição partidária (MÉNY, 1990, p. 67).

\footnotetext{
1 Agradecemos a Michael Coppedge, Marta Fraile, Anna Grzymala-Busse, Frances Hagopian, Kevin Krause, Ignacio Lago, Carol Mershon, José Ramón Montero, Richard Rose, Edurne Zoco e dois pareceristas anônimos pelos comentários. Edurne Zoco, Angel Alvárez, Lorenzo Brusattin e Terence Merritt forneceram auxílio à pesquisa. Peter Baker, Eugene Bartkus, Viva Bartkus, Pradeep Chhibber, Dwight Dyer, Kevin Krause, Bong.jun Ko, Mark Jubulis, Vello Pettai, Marina Popescu, Gabor Toka, Edward Rakhimkulov e Edurne Zoco nos ajudaram a identificar cisões, fusões e mudanças de nomes de partidos.
} 
MAINWARING, S.;TORCAL, M. Teoria e institucionalização dos sistemas partidários...

$\mathrm{Na}$ conclusão, argumentamos que a fraca institucionalização tem conseqüências negativas para a accountability eleitoral. Sistemas partidários pouco institucionalizados são mais vulneráveis a permitir que políticos anti-partidos cheguem ao poder, causando efeitos adversos na democracia, como por exemplo, Fujimori, no Peru entre 1990-2000, e Hugo Chávez, na Venezuela de 1998 até o presente.

Até a década de 1980, a literatura teórica sobre partidos e sistemas partidários ou concentrava-se em sistemas bem institucionalizados ou os pressupunha implicitamente. Havia poucas democracias ou semi-democracias com sistemas partidários pouco institucionalizados. Porém, desde o início da terceira onda de democratização (HUNTINGTON, 1991), esses sistemas se tornaram lugar comum nos regimes políticos competitivos. Eles têm características e dinâmicas diferentes dos sistemas bem institucionalizados. Os cientistas sociais precisam modificar a literatura teórica dominante para compreender esses sistemas partidários menos institucionalizados.

Este artigo baseia-se em Mainwaring e Scully (1995) e Mainwaring (1999, p. 22-39), que geraram grande parte do trabalho contemporâneo sobre institucionalização do sistema partidário. Avançamos em relação a esses trabalhos mais antigos de quatro maneiras. Primeiro, oferecemos mais provas empíricas sistemáticas, usando surveys em vários países para demonstrar algumas das proposições anteriores sobre essa institucionalização. Com base nesses dados, também desenvolvemos novos indicadores para avaliar a força das raízes programáticas dos partidos na sociedade. Em segundo lugar, analisamos uma variedade maior de países do que naqueles trabalhos e outros estudos anteriores sobre esse tema. Em terceiro lugar, analisamos alguns aspectos novos da teoria dos sistemas partidários, que aqueles trabalhos não trataram em detalhe; em particular, questionamos o pressuposto dos vínculos programáticos e ideológicos que permeia uma parte da literatura. Por fim, apresentamos testes mais rigorosos para algumas proposições empíricas, ao mesmo tempo que abandonamos algumas afirmações difíceis de testar sobre as conseqüências da baixa institucionalização. A segunda metade do artigo, ao mesmo tempo que desenvolve os conceitos e teorias presentes nos trabalhos citados, apresenta novos argumentos e evidências.

Diferentemente de Mainwaring e Scully (1995), não comparamos sistemas partidários em todas as quatro dimensões de sua institucionalização. Devido às dificuldades de se obter informações empíricas válidas comparáveis para todas as quatro dimensões em uma ampla gama de países, preferimos desenvolver alguns pontos em maior profundidade e para um grande número de países do que oferecer uma discussão superficial de todas as dimensões. Nossa análise limita-se 
exclusivamente a democracias e semi-democracias ${ }^{2}$; os partidos que funcionam em regimes autoritários estão fora de nossa esfera de estudo.

\section{Comparando sistemas partidários: o nível de institucionalização}

Um sistema partidário é um conjunto de partidos que interagem de maneiras padronizadas. Essa definição implica três diferenças entre sistemas e nãosistemas. Primeiro, como Sartori (1976) mostrou, um sistema deve ter pelo menos dois elementos constitutivos; portanto, precisa ter ao menos dois partidos. Segundo, a noção de interações padronizadas sugere que há algumas regularidades na distribuição do apoio eleitoral por partidos ao longo do tempo, mesmo que alguns deles ascendam e outros declinem. Terceiro, a idéia de um sistema implica alguma continuidade nos componentes que o formam. Portanto, "sistema partidário" implica alguma continuidade nos partidos, ou seja, a institucionalização das agremiações.

Os sistemas partidários variam em muitas dimensões, mas os cientistas sociais se empenham em identificar as mais importantes para facilitar a classificação e a comparação. Como, então, deveriam os cientistas sociais comparar e classificar os sistemas partidários? Sartori (1976) identificou duas dimensões desses sistemas como sendo de particular importância: o número de partidos relevantes e o grau de polarização ideológica. Porém, conceituou inadequadamente uma propriedade igualmente importante dos sistemas partidários: o nível de institucionalização.

Em sua discussão sobre a diferença entre sistemas partidários consolidados e não-sistemas, Sartori (1976, p. 244-248) foi pioneiro ao reconhecer a importância da institucionalização (que ele chamou de "consolidação"). No entanto, discordamos de três aspectos de sua conceituação de institucionalização. Primeiro, ele postulou uma dicotomia entre sistemas consolidados e não-sistemas, enquanto nós julgamos muito mais útil conceber a institucionalização como um continuum. Nada na definição de "sistema" justifica uma demarcação rígida dicotômica entre um sistema e um não-sistema, desde que haja algum padrão na competição entre partidos e alguma continuidade nos principais partidos do sistema. Esses dois critérios são fáceis de cumprir minimamente. As categorias dicotômicas de Sartori ignoram variações importantes dentro de cada uma dessas categorias. Além disso, uma dicotomia requer um ponto de corte preciso e inevitavelmente arbitrário: um caso precisa ser classificado ou como consolidado ou como não-consolidado.

\footnotetext{
2 Seguimos as definições de democracia e semi-democracia de Mainwaring, Brinks e Pérez-Liñan (2001). Incluímos ambas quando nos referimos a regimes políticos competitivos.
} 
MAINWARING, S.;TORCAL, M. Teoria e institucionalização dos sistemas partidários...

Em segundo lugar, Sartori estabelece um patamar excessivamente alto para o que constitui um sistema partidário. Por exemplo, ele sustentou que a Colômbia não tinha um sistema partidário na década de 1970, quando, na verdade, o país tinha um dos mais antigos do mundo. Liberais e conservadores eram os principais adversários eleitorais havia décadas, sempre quando as eleições eram relativamente livres e legítimas, e ambos os partidos tinham fortes raízes na sociedade.

Em terceiro lugar, pelo fato de que considerava os não-sistemas como exteriores à sua teorização principal e não examinava a variação na institucionalização entre sistemas partidários ou entre o que ele considerava não. sistemas, Sartori relegou a institucionalização a um segundo plano. Por exemplo, as considerações sobre institucionalização estão totalmente ausentes de sua classificação dos sistemas partidários. Ao contrário, acreditamos que a institucionalização deve estar no centro do palco, pois algumas das diferenças mais importantes entre sistemas partidários giram em torno das diferenças em institucionalização.

Uma classificação dos sistemas partidários baseada no número de partidos e no nível de polarização negligencia diferenças substanciais no grau de institucionalização e, portanto, como a competição entre partidos funciona em contextos menos institucionalizados. Ao comparar e classificar os sistemas partidários para além das democracias industriais avançadas, os cientistas políticos que trabalham sobre a América Latina (BENDEL, 1993; COPPEDGE, 1998, p. 559. 561; KITSCHELT, 2003; MAINWARING, 1999; MAINWARING e SCULLY, 1995; MOLINA e PÉREZ, 2004; PAYNE et al., 2002, p. 127-154; SCHEDLER, 1995; VAN COTT, 2000), África (KUENZI e LAMBRIGHT, 2001), Ásia (JOHNSON, 2002; STOCKTON, 2001) e as regiões pós-comunistas (BIELASIAK, 2002; GRZYMALABUSSE, 2002; MAIR, 1997, p. 175-198; MARKOWSKI, 2000; MOSER, 1999 e 2001; ROSE e MUNRO, 2003; STONER-WEISS, 2001; TAVITS, 2005; TÓKA, 1997) reconheceram cada vez mais a necessidade de dar atenção ao nível de institucionalização, além das duas dimensões de Sartori ${ }^{3}$. Sistemas partidários institucionalizados estruturam em alto grau o processo político. Em sistemas fluidos, os partidos são, de alguma forma, atores importantes, mas não possuem o mesmo efeito estruturador.

\footnotetext{
${ }^{3}$ Nosso foco é sobre sistemas partidários. Outros estudiosos trataram da institucionalização dos partidos (DIX, 1992; GUNTHER e HOPKIN, 2002; HUNTINGTON, 1968, p. 12.28; JANDA, 1980; LEVITSKY, 2003; MÉNY, 1990; PANEBIANCO, 1988; RANDALL e SVÅSAND, 2002). A institucionalização dos partidos nas democracias está forte e positivamente correlacionada à institucionalização do sistema partidário, mas a relação não é linear, como observaram Mainwaring e Scully (1995, p. 20-21), Randall e Svåsand (2002), Stockton (2001) e Wallis (2003).
} 
Institucionalização refere-se a um processo pelo qual uma prática ou organização se torna bem estabelecida e amplamente conhecida, senão universalmente aceita. Os atores desenvolvem expectativas, orientações e comportamentos baseados na premissa de que essa prática ou organização prevalecerá no futuro previsível. Em política, institucionalização significa que os atores políticos têm expectativas claras e estáveis em relação ao comportamento dos outros atores. Nas palavras de Huntington (1968, p. 12), “institucionalização é o processo pelo qual organizações e procedimentos adquirem valor e estabilidade". Desse modo, um sistema partidário institucionalizado é aquele em que os atores desenvolvem expectativas e comportamentos baseados na premissa de que os contornos e as regras fundamentais da competição e do comportamento partidários prevalecerão no futuro previsível. Num sistema partidário institucionalizado, os principais partidos e seu comportamento serão estáveis. A noção de institucionalização não deve ser teleológica, nem o processo é linear; não há progressão necessária de uma institucionalização fraca para uma maior. Os sistemas partidários podem se desinstitucionalizar, como mostram os casos da Itália, do Peru e da Venezuela nos anos 1990.

Seguindo Mainwaring (1999, p. 22-39) e Mainwaring e Scully (1995), conceituamos quatro dimensões da institucionalização do sistema partidário. Primeiro, sistemas mais institucionalizados manifestam considerável estabilidade nos padrões de competição entre partidos (PRZEWORSKI, 1975). Essa é a dimensão mais fácil de medir e talvez a mais importante, porque a institucionalização está conceitualmente muito vinculada à estabilidade.

Em segundo lugar, em sistemas mais institucionalizados, os partidos têm raízes fortes na sociedade, a maioria dos eleitores tem ligações partidárias e algumas associações de interesse estão intimamente ligadas a eles. Um forte enraizamento partidário na sociedade ajuda a proporcionar a regularidade na competição eleitoral que a idéia de institucionalização implica. Raízes na sociedade e estabilidade da competição entre partidos, embora analiticamente separáveis, estão entrelaçadas porque o forte enraizamento social estabiliza a competição. Se a maioria dos cidadãos apóia o mesmo partido de uma eleição para outra, há menos eleitores flutuantes e, portanto, menor probabilidade de mudanças eleitorais em massa que se refletem em alta volatilidade. Ao contrário, onde os partidos possuem raízes fracas na sociedade, é provável que mais eleitores troquem de partido de uma eleição para outra, abrindo assim a possibilidade de uma maior volatilidade.

Em terceiro lugar, em sistemas mais institucionalizados, os atores políticos conferem legitimidade aos partidos, considerando-os uma parte necessária da política democrática, mesmo quando criticam determinados partidos e manifestam ceticismo em relação aos partidos em geral (TORCAL, GUNTHER e MONTERO, 2002). A legitimidade ajuda a estabilizar os sistemas partidários e, portanto, é uma dimensão atitudinal significativa da institucionalização. 
MAINWARING, S.;TORCAL, M. Teoria e institucionalização dos sistemas partidários...

Por fim, em sistemas mais institucionalizados, as organizações partidárias não estão subordinadas aos interesses de uns poucos líderes ambiciosos; elas adquirem um status e um valor independente próprio (HUNTINGTON, 1968, p. 12. $24)^{4}$. A institucionalização partidária é limitada quando um partido é instrumento pessoal de um líder ou de um pequeno grupo (JANDA, 1980). Quando os partidos eleitoralmente bem sucedidos são veículos personalistas, o nível de institucionalização do sistema é baixo nessa quarta dimensão.

Embora discordemos de Sartori quando concebemos a institucionalização como um continuum, em vez de uma dicotomia, ele merece grande crédito por reconhecer que há profundas diferenças nos sistemas partidários conforme o nível de institucionalização. Após sua obra clássica, essa questão foi completamente esquecida até Bendel (1993) e Mainwaring e Scully (1995).

Os sistemas partidários caracterizados por um grau baixo de institucionalização podem ser denominados fluidos ou fracamente institucionalizados. A institucionalização é uma variável contínua que vai de sistemas partidários institucionalizados a fluidos. Comparados com sistemas mais institucionalizados, os sistemas fluidos caracterizam-se por menos regularidade nos padrões da competição, raízes mais fracas na sociedade, menor legitimidade conferida aos partidos e organizações partidárias mais débeis, dominadas freqüentemente por líderes personalistas.

\section{A estabilidade da competição partidária: volatilidade eleitoral}

Para desenvolver o argumento de que os sistemas partidários competitivos contemporâneos diferem em aspectos importantes que não podem ser captados pela tipologia de Sartori, comparamos 39 países conforme a primeira dimensão da institucionalização: a regularidade dos padrões de competição partidária. Das quatro dimensões mencionadas, é a mais fácil de medir sistematicamente, comparando especificamente a volatilidade eleitoral. Essa volatilidade refere-se à transferência agregada de votos de um partido para os outros, de uma eleição para a próxima (PEDERSEN, 1983; PRZEWORSKI, 1975; ROBERTS e WIBBEL, 1999). Ela

\footnotetext{
4 Uma vez que a discussão de Huntington sobre institucionalização é bem conhecida, vale a pena observar que nosso conceito difere do dele. Nosso foco é sobre os sistemas partidários, o dele era sobre partidos. Mais importante, ele considerava os partidos mais institucionalizados quando eram mais autônomos em relação aos grupos sociais. Ao contrário, nós acreditamos que vínculos fortes entre partidos e grupos sociais manifestam raízes partidárias mais profundas na sociedade e maior institucionalização.
} 
é computada somando-se a mudança líquida em porcentagem de votos ganhos ou perdidos por cada partido de uma eleição para outra e depois dividindo-se por dois ${ }^{5}$

A Tabela 1 mostra a volatilidade eleitoral para eleições da câmara baixa do período pós-1978 em 39 democracias e semi-democracias. Limitamos a seleção de casos a países que até 2003 haviam tido pelo menos três eleições consecutivas para a câmara baixa, quando o escore combinado atribuído pela Freedom House ao país era 10 ou menos ${ }^{6}$. Os países com um escore combinado médio de 11 ou mais tinham regimes autoritários e são classificados pela Freedom House como "não livres". Em regimes autoritários, os partidos possuem funções diferentes do que nas democracias e semi-democracias. Esses regimes não permitem eleições livres e justas, seu controle das eleições favorece o partido governante e tende a limitar a volatilidade eleitoral. Portanto, costuma ser enganador comparar a volatilidade eleitoral entre os dois tipos de regimes. Assim, somente o período democrático mais recente é levado em conta nos países onde houve uma interrupção da democracia e, dessa forma, usamos apenas eleições posteriores a $1978^{7}$.

A Tabela 1 inclui países da rodada 1995-97 do World Values Survey (WVS) e do Comparative Study of Electoral Systems (CSES) [Estudo Comparativo de Sistemas Eleitorais] $]^{8}$. Entre os países do WVS que cumpriam o critério da Freedom House em pelo menos três eleições consecutivas, incluímos todos aqueles com uma população de pelo menos dez milhões de habitantes. A Tabela 1 inclui também sete países (Dinamarca, Noruega, Portugal, Suécia, Suíça, Letônia e Lituânia) que tinham menos de dez milhões de habitantes com o objetivo de analisar alguns países menores, e Bolívia e Equador para reduzir a sub-representação dos países pobres.

\footnotetext{
${ }^{5}$ Quando um partido se cinde em dois ou mais partidos entre a eleição T1 e a T2, comparamos seu total T2 com o maior partido resultante da cisão. Tratamos então o menor como se não tivesse obtido votos na eleição T1. Quando dois ou mais partidos se fundiram e criaram uma nova organização, calculamos a volatilidade usando o partido original com a maior porcentagem. Se dois ou mais partidos se fundiram para a eleição T2, mas competiram na eleição T1 como partidos separados, admitimos que aquele com menos votos desapareceu na eleição T2. Demos um valor zero para esse partido em T2 e contamos sua parte dos votos em T1 como sua porcentagem de mudança. Quando um partido mudou de nome, mas apresentou uma continuidade óbvia com um partido anterior, ele foi contado como sendo a mesma organização. Tratamos usualmente os partidos independentes como uma categoria porque nos faltam dados necessários para comparar seus resultados individuais de uma eleição para outra.

${ }^{6}$ A Freedom House publica um relatório anual sobre o estado das liberdades civis e dos direitos políticos na maioria dos países. Os escores variam de 1 (melhor) a 7 (pior). Combinamos os dois escores, criando um índice de 2 (mais democrático) a 14 (mais autoritário).

7 Não incluímos Bangladesh e as Filipinas devido à ausência de resultados eleitorais completos. Para o Equador, usamos resultados para deputados selecionados em um distrito de âmbito federal, não os resultados separados para deputados federais eleitos em distritos de âmbito provinciais.

8 Para Bélgica, França, Itália, Holanda, Reino Unido e Alemanha Ocidental, usamos o European Election Study 1994.
} 
MAINWARING, S.;TORCAL, M. Teoria e institucionalização dos sistemas partidários...

Tabela 1

Volatilidade eleitoral, IDH, PIB per capita e escores da Freedom House, 39 países

\begin{tabular}{|c|c|c|c|c|c|}
\hline País & $\begin{array}{l}\text { Volatilidade } \\
\text { eleitoral média, } \\
\text { câmara baixa }\end{array}$ & $\begin{array}{l}\text { Eleições incluídas } \\
\text { para volatilidade }\end{array}$ & $\begin{array}{c}\text { Índice de } \\
\text { Desenvolvimento } \\
\text { Humano (IDH) } 2001\end{array}$ & $\begin{array}{l}\text { PIB per capita (US\$ com } \\
\text { Paridade do Poder de } \\
\text { Compra) } 2001\end{array}$ & $\begin{array}{c}\text { Escores da Freedom } \\
\text { House combinados } \\
2001-2002\end{array}$ \\
\hline Estados Unidos & 3,2 & 1978-2002 & 0,937 & 34.320 & $2, \mathrm{~L}$ \\
\hline Austrália & 6,4 & 1980-2001 & 0,939 & 25.370 & $2, \mathrm{~L}$ \\
\hline Grécia & 6,9 & 1981-2000 & 0,892 & 17.440 & $4, \mathrm{~L}$ \\
\hline Reino Unido & 8,2 & 1979-2001 & 0,930 & 24.160 & $3, \mathrm{~L}$ \\
\hline Alemanha & 8,7 & 1980-2002 & 0,921 & 25.350 & ---- \\
\hline Suíça & 9,4 & 1979-2003 & 0,932 & 28.100 & $2, \mathrm{~L}$ \\
\hline Bélgica & 11,5 & 1978-2003 & 0,937 & 25.520 & $3, \mathrm{~L}$ \\
\hline Dinamarca & 12,2 & 1979-2001 & 0,930 & 29.000 & $2, \mathrm{~L}$ \\
\hline Suécia & 13,5 & 1979-2002 & 0,941 & 24.180 & $2, \mathrm{~L}$ \\
\hline Noruega & 14,1 & 1981-2001 & 0,944 & 29.620 & $2, \mathrm{~L}$ \\
\hline Portugal & 14,1 & 1979-2002 & 0,896 & 18.150 & $2, \mathrm{~L}$ \\
\hline Espanha & 16,5 & 1979-2000 & 0,918 & 20.150 & $3, \mathrm{~L}$ \\
\hline Holanda & 16,6 & 1981-2003 & 0,938 & 27.190 & $2, \mathrm{~L}$ \\
\hline Chile & 16,7 & 1989-2001 & 0,831 & 9.190 & $4, \mathrm{~L}$ \\
\hline França & 17,5 & 1978-2002 & 0,925 & 23.990 & $3, \mathrm{~L}$ \\
\hline Japão & 18,6 & 1979-2000 & 0,932 & 25.130 & $3, \mathrm{~L}$ \\
\hline Taiwan & 18,7 & 1996-2001 & ---- & ------ & $3, \mathrm{~L}$ \\
\hline Itália & 22,1 & 1979-2001 & 0,916 & 24.670 & $3, \mathrm{~L}$ \\
\hline Colômbia & 22,1 & 1978-2002 & 0,779 & 7.040 & $8, \mathrm{PL}$ \\
\hline México & 22,7 & $1988-2000$ & 0,800 & 8.430 & $5, \mathrm{~L}$ \\
\hline Brasil & 24,1 & 1986-2002 & 0,777 & 7.360 & $6, \mathrm{PL}$ \\
\hline Coréia do Sul & 24,6 & $1988-2000$ & 0,879 & 15.090 & $4, \mathrm{~L}$ \\
\hline Argentina & 24,9 & 1983-2001 & 0,849 & 11.320 & $6, \mathrm{PL}$ \\
\hline Índia & 25,0 & 1980-1999 & 0,590 & 2.840 & $5, \mathrm{~L}$ \\
\hline Hungria & 25,1 & 1990-2002 & 0,837 & 12.340 & $3, \mathrm{~L}$ \\
\hline República Tcheca & 25,7 & 1990-2002 & 0,861 & 14.720 & $3, \mathrm{~L}$ \\
\hline Venezuela & 31,3 & $1978-2001$ & 0,775 & 5.670 & $8, \mathrm{PL}$ \\
\hline Equador & 36,4 & 1979-1998 & 0,731 & 3.280 & $6, \mathrm{PL}$ \\
\hline Bulgária & 36,8 & 1990-2001 & 0,795 & 6.890 & $4, \mathrm{~L}$ \\
\hline Eslovênia & 38,2 & $1992-2000$ & 0,881 & 17.130 & $3, \mathrm{~L}$ \\
\hline Bolívia & 39,8 & 1980-2002 & 0,672 & 2.300 & $4, \mathrm{~L}$ \\
\hline Estônia & 42,4 & 1992-2003 & 0,833 & 10.170 & $3, \mathrm{~L}$ \\
\hline Polônia & 46,6 & 1991-2001 & 0,841 & 9.450 & $3, \mathrm{~L}$ \\
\hline Lituânia & 49,2 & 1992-2000 & 0,824 & 8.470 & $3, \mathrm{~L}$ \\
\hline Rússia & 50,0 & 1993-1999 & 0,779 & 7.100 & $10, \mathrm{PL}$ \\
\hline Peru & 51,9 & 1980-2001 & 0,752 & 4.570 & $4, \mathrm{~L}$ \\
\hline Romênia & 53,0 & 1990-2000 & 0,773 & 5.830 & $4, \mathrm{~L}$ \\
\hline Letônia & 58,2 & 1993-2002 & 0,811 & 7.730 & $3, \mathrm{~L}$ \\
\hline Ucrânia & 59,2 & 1994-2002 & 0,766 & 4.350 & 8,PL \\
\hline
\end{tabular}

Fontes: Human Development Report (2003) para o IDH e o valor do PIB em 2001.

Escores da Freedom House em: http://polisci.la.psu.edu/faculty/Casper/FHratings.pdf.

$\mathrm{L}=$ Livre; $\mathrm{PL}=$ Parcialmente Livre. 
Os sistemas partidários variam de muito estáveis (Estados Unidos, Austrália etc.) a extremamente voláteis (Ucrânia, Letônia, Romênia, Peru, Rússia, Polônia e Estônia). A mudança eleitoral é, em média, muito maior nas democracias e semidemocracias em desenvolvimento do que nas democracias industriais avançadas, ainda que nestas últimas, como Dalton, McAllister e Wattenberg (2000) afirmam, a volatilidade tenha aumentado em décadas recentes. Nos Estados Unidos, o resultado da eleição anterior para a câmara baixa serve como excelente preditor do resultado da eleição subseqüente por partido, com um erro médio de apenas 3,2\%. Em contraste, na Ucrânia, o procedimento idêntico oferece pouca capacidade de previsão, com um erro médio de 59,2\% (dezoito vezes maior do que nos EUA). Lipset e Rokkan (1967) caracterizaram os sistemas partidários da Europa Ocidental como "congelados". Ao contrário, muitos sistemas partidários contemporâneos em regimes políticos competitivos são altamente fluidos.

Os escores de volatilidade ressaltam a vantagem de conceber a institucionalização como uma variável contínua e qualquer tentativa de estabelecer um ponto de corte dicotômico seria arbitrária. A mesma observação se aplica aos outros indicadores desenvolvidos mais adiante neste artigo.

A Tabela 1 apresenta também o Índice de Desenvolvimento Humano (IDH) de 2001 para esses 39 países (tal como registrado no Human Development Report de 2003) e seus escores da Freedom House de 2003. Em geral, os países mais ricos possuem volatilidade eleitoral menor. Em uma regressão OLS com a volatilidade média dos países como a variável dependente e o IDH deles como a única variável independente, esta última foi significativa no nível 0,000 e teve um forte impacto substantivo; cada aumento de 0,100 no IDH levou a uma diminuição esperada de $12,5 \%$ na volatilidade eleitoral. O IDH respondeu por $46,3 \%$ da variação em escores de volatilidade. Numa segunda regressão OLS, com apenas uma variável independente, o PIB per capita foi um preditor ainda mais forte da volatilidade, respondendo por $60,6 \%$ da variação nos escores de volatilidade. A variável PIB per capita foi significativa no nível de 0,000 e teve um forte impacto substantivo; um aumento de US\$1.000 nela produz uma diminuição esperada de 1,29\% na volatilidade eleitoral. Esses resultados mostram que as democracias industriais avançadas possuem sistemas partidários mais estáveis do que as democracias e semi-democracias menos desenvolvidas. A correlação entre renda per capita dos países e sua volatilidade eleitoral média foi um impressionante $-0,78$, significativa no nível de 0,000 (2-tailed). Os dezesseis países com o IDH mais alto (IDH $\geq 0,892)$ estão entre os dezoito países com a volatilidade eleitoral mais baixa.

As causas da forte correlação entre um alto nível de desenvolvimento e a baixa volatilidade eleitoral requerem pesquisas além do que é possível fazer aqui; oferecemos apenas algumas breves reflexões. O fato de que a maioria dos sistemas partidários da Europa Ocidental tenha se estabilizado antes da Segunda Guerra 
MAINWARING, S.;TORCAL, M. Teoria e institucionalização dos sistemas partidários...

Mundial (BARTOLINI e MAIR, 1990; LIPSET e ROKKAN, 1967), quando esses países tinham padrões de vida muito mais baixos do que os atuais, indica que a principal explicação não é o argumento baseado na modernização, segundo o qual um nível mais alto de desenvolvimento causa volatilidade eleitoral mais baixa. Na maioria do que agora são democracias industriais avançadas, os partidos foram veículos de integração social e política das massas de novos cidadãos (CHALMERS, 1964; PIZZORNO, 1981). Eles construíram organizações integradoras e solidificaram fortes lealdades. Na maioria dos países de democratização tardia, os partidos ocuparam um lugar menos central na luta para expandir a cidadania e nunca tiveram as funções sociais de amplo alcance ou fomentaram fortes identidades, tal como fizeram nas democracias mais antigas (GUNTHER e DIAMOND, 2003). Essas diferenças de padrões históricos (path dependence) ajudam a explicar as altas correlações entre um nível maior de desenvolvimento e um sistema partidário mais estável. O mau desempenho econômico em muitos países menos desenvolvidos contribuiu também para a alta volatilidade eleitoral (REMMER, 1991; ROBERTS e WIBBLES, 1999). Um fator contribuinte final dessa alta volatilidade em muitos países menos desenvolvidos são as freqüentes mudanças do lado da oferta, na medida em que as elites políticas mudam de um partido para outro (ROSE e MUNRO, 2003).

Converse (1969) sustentou que os sistemas partidários se tornariam mais estáveis ao longo do tempo, à medida que os eleitores passassem a se identificar com determinados partidos ${ }^{9}$. Porém, pesquisas recentes indicaram que a maioria dos eleitores aprende rapidamente a localizar as posições dos partidos (KITSCHELT et al., 1999) e que os sistemas partidários em países menos desenvolvidos não tendem, em média, a se tornar mais estáveis ao longo do tempo (BIELSIAK, 2002). Nossos dados sobre volatilidade eleitoral parecem confirmar esse argumento. Nos dezenove países da Tabela $1 \mathrm{com}$ IDH menor que 0,850, para o primeiro período eleitoral incluído nessa tabela, a volatilidade eleitoral foi, em média, 38,2\%. Nos períodos eleitorais posteriores, a volatilidade para esses países foi, em média, $33,1 \%(n=19), 34,8 \%(n=16), 35,0 \%(n=10)$ e $27,9 \%(n=7)$. Nenhuma das médias de volatilidade após o primeiro período eleitoral difere estatisticamente (em $p<0,10$, 2.tailed) da média de $38,2 \%$ para o primeiro período. Portanto, não há tendência estatisticamente significante de diminuição da volatilidade ao longo do tempo. Desse modo, os dados sobre volatilidade indicam que a institucionalização não é linear ou teleológica. Rose e Munro (2003) chamam esse fenômeno de longo período sem institucionalização de "competição sem institucionalização". A institucionalização fraca (e a alta volatilidade) poderia continuar por um longo tempo.

\footnotetext{
9 Janda (1980) também sustentou que a institucionalização dos partidos é uma questão de tempo. Tavits (2005) afirma que na Europa pós-comunista, a volatilidade aumentou primeiro, para depois diminuir.
} 
Durante o período pós-1980, a maioria dos países não experimentou grandes mudanças em volatilidade eleitoral de uma eleição para outra. A correlação entre escores de países no primeiro período eleitoral usado na Tabela 1 e o segundo é 0,68 ( $n=39)$ (significativa no nível de 0,000); entre o segundo e o terceiro período, é $0,83(n=34)$ (significativa no nível de 0,000), entre o terceiro e o quarto, é 0,73 $(n=27)$ (significativa no nível de 0,000) e entre o quarto e o quinto, é 0,69 (n=23) (significativa no nível de 0,000). Mesmo ao longo de um período extenso, as correlações mantêm níveis moderadamente fortes. Por exemplo, a correlação entre volatilidade no primeiro e no quinto período é 0,54, significativa no nível de 0,008, e entre o segundo e o quinto é 0,69, significativa no nível de 0,000. Poucos países exibem declínios marcantes em volatilidade ao longo do tempo (por exemplo, o Brasil após 1994), enquanto outros poucos mostram aumentos notáveis (por exemplo, a Itália depois de 1993, a Venezuela após 1988), mas a volatilidade é bastante estável na maioria dos países.

\section{Raízes partidárias e voto ideológico}

A segunda dimensão da institucionalização do sistema partidário é a ancoragem dos partidos na sociedade. Em sistemas partidários mais institucionalizados, os partidos criam raízes sociais fortes e estáveis. Onde isso acontece, a maioria dos eleitores sente-se ligado a um partido e vota regularmente em seus candidatos.

A maioria das teorias sobre os motivos da fidelidade de indivíduos a partidos - ou, dito de outra forma, sobre porque os partidos criam raízes na sociedade concentra-se nos vínculos ideológicos ou programáticos entre eleitores e partidos. 0 pressuposto da existência desses vínculos fortes caracteriza os modelos espaciais do voto de proximidade e os direcionais, a literatura sobre o esquema direitaesquerda (FUCHS e KLINGEMANN, 1990), as abordagens dos sistemas partidários baseadas na clivagem social (LIPSET e ROKKAN, 1967) e algumas importantes teorias sobre realinhamento partidário nas democracias industriais avançadas (INGLEHART, 1984, 1990; KITSCHELT, 1994). Concordamos que vínculos programáticos ou ideológicos são um meio importante para estabilizar a competição eleitoral (embora vínculos clientelistas e tradicionais/afetivos também possam causar esse efeito); mas discordamos que tais vínculos sejam fortes na maioria dos sistemas partidários e, ao contrário, mostramos que há uma ampla variação na força dos vínculos ideológicos. 
MAINWARING, S.;TORCAL, M. Teoria e institucionalização dos sistemas partidários...

Os modelos espaciais do voto são muito importantes para entender como os indivíduos desenvolvem ligações a determinados partidos e por que os partidos criam raízes profundas na sociedade. O modelo de proximidade espacial está associado a Budge (1994), Cox (1990), Downs (1957), Enelow e Hinich (1984), Hinich e Munger (1994) e Westholm (1997), entre outros. Hinich e Munger (1994) criaram um modelo espacial de proximidade particularmente sofisticado: sustentam que a competição espacial não ocorre necessariamente ao longo de uma dimensão econômica esquerda-direita ${ }^{10}$, mas ainda pressupõem que os eleitores escolhem um partido ou candidato com base na ideologia, que serve de atalho para a decisão eleitoral. Nessa teoria, os indivíduos desenvolvem ligações com partidos porque acreditam que esses partidos defendem melhor os seus interesses. A explicação desses autores sobre por que um grande número de indivíduos adere a partidos gira em torno da congruência ideológica entre eleitores e seus partidos preferidos.

Os modelos espaciais direcionais concordam que os eleitores escolhem um candidato ou partido com base na posição ideológica, mas diferem do modelo anterior em um aspecto fundamental. Nas teorias direcionais, os cidadãos não votam conforme a proximidade do partido em relação a eles na escala esquerda. direita, mas de acordo com a orientação ideológica do partido em algumas questões em relação às quais o eleitor tem uma preferência intensa (RABINOWITZ e MACDONALD, 1989; RABINOWITZ, MACDONALD e LISTHAUG, 1991). A abordagem direcional compartilha com os modelos de proximidade a idéia de que a posição ideológica determina as preferências dos eleitores por candidatos ou partidos e é responsável pelas raízes partidárias na sociedade ${ }^{11}$.

Outro conjunto importante da literatura sobre partidos e eleitores pressupõe implicitamente que o voto é programático ou ideológico ${ }^{12}$. A teoria da clivagem social dos sistemas partidários de Lipset e Rokkan (1967) supõe que os eleitores

\footnotetext{
10 Discordamos que a dimensão esquerda-direita necessariamente se refere exclusivamente ou mesmo principalmente a uma dimensão econômica. Ao contrário, ela incorpora questões que mudam historicamente, entre as quais as questões econômicas foram proeminentes na maioria das democracias industriais avançadas. Em muitas destas, religião foi um melhor preditor da posição esquerda-direita do que a classe. Nas duas últimas décadas, cada vez mais, o pós-materialismo se tornou um importante preditor da posição esquerda-direita (INGLEHART, 1984 e 1990; KITSCHELT, 1994).

11 Iversen (1994b) e Merrill e Grofman (1999) integram os modelos de proximidade espacial e os direcionais. Iversen (1994a) integra a teoria espacial com um entendimento de que os partidos influenciam os eleitores. Hibbing e Theiss-Morse (2002) criticam a teoria espacial; eles argumentam que o voto ideológico é menos importante do que os modelos espaciais afirmam.

12 Uma importante abordagem contrastante ao voto ideológico é o voto baseado no desempenho do governo. Por exemplo, a obra seminal de Fiorina (1981) supõe o voto com base nas avaliações retrospectivas dos benefícios proporcionados por políticas públicas. As teorias sobre o voto econômico (KIEWET e KINDER, 1979) também se baseiam na suposição de que os eleitores fazem suas escolhas eleitorais em função do desempenho do governo. Ver Sánchez-Cuenca (2003) para uma síntese das abordagens do voto baseadas em ideologia e em desempenho.
} 
identificam seus interesses com base em suas posições sociológicas na sociedade classe, religião, etnia ou nacionalidade e residência urbana/rural. Nesse argumento, está implícito que alguns partidos defendem programática ou ideologicamente os interesses de diferentes setores da sociedade e que os indivíduos formam suas preferências partidárias com base nos interesses programáticos e ideológicos que resultam de suas posições sociais (ver também BARTOLINI e MAIR, 1990; SCULLY, 1992; VALENZUELA, 1997).

Outra tradição acadêmica importante considera o esquema esquerda-direita, que sintetiza as orientações ideológicas, como uma âncora psicológica estabilizadora que influencia o voto. De acordo com essa literatura, os indivíduos determinam suas preferências partidárias com base em suas orientações ideológicas (INGLEHART e KLINGEMANN, 1976; KLINGEMANN, 1979; INGLEHART, 1979; LAPONCE, 1981; FUCHS e KLINGEMANN, 1990; FLEURY e LEWIS-BECK, 1993; KNUTSEN, 1997).

Em suma, três importantes tradições acadêmicas supõem que os vínculos entre eleitores e partidos são programáticos ou ideológicos. Em contraste, mostramos que há grande variação no grau em que a competição partidária em diferentes países é programática ou ideológica. O voto ideológico, tal como medido pelo tradicional esquema esquerda-direita, varia enormemente ${ }^{13}$.

A última coluna da Tabela 2 fornece uma medida da variação do voto ideológico entre países baseada nos resultados de uma análise de regressão logística com pares de partidos como variável dependente (colunas 2 a 5). Nessa análise, o voto tal como expresso por respondentes de surveys é a variável dependente dicotômica e a escala esquerda-direita de 1 a 10 é a única variável independente. A análise limita-se a alguns países que tiveram um escore Freedom House combinado de 10 ou menos em 1996. Nos restringimos aos três maiores partidos (de acordo com o número de respondentes que expressaram uma preferência partidária no survey) de cada país ${ }^{14}$. Para um escore em nível nacional, utilizamos os resultados de duas simulações (não apresentadas no texto) baseadas nos coeficientes estimados da regressão logística. A primeira simulação estimou a probabilidade de um eleitor A escolher o partido i e não o partido $j$, considerando A localizado no ponto 3,25 da escala esquerda-direita (3,25 é o ponto mediano exato

\footnotetext{
13 A escala esquerda-direita constitui um bom resumo da ideologia na maioria dos países (ALCÁNTARA, 1995; DALTON, 1985; INGLEHART, 1984; SANI e SARTORI, 1983). Em muitos países latino-americanos, um grande número de eleitores não tem uma boa compreensão da escala esquerda-direita, mas do mesmo modo, não tem uma compreensão sofisticada das questões programáticas. Numa comunicação pessoal, Kevin Krause observou que em alguns países com divisões étnicas significativas - por exemplo, a Eslováquia - as posições esquerda-direita não constituem um bom resumo da ideologia.

14 Para os Estados Unidos, usamos somente dois partidos porque o terceiro partido era eleitoralmente insignificante.
} 
entre o centro e o ponto mais à esquerda). A segunda simulação estimou a probabilidade de um eleitor $A$ escolher o partido $i$ e não o $j$ se $A$ estivesse localizado no ponto 7,75 na escala esquerda-direita (7,75 é o ponto mediano exato entre o centro e o ponto mais à direita, 10,00). A coluna intitulada "probabilidades da primeira diferença" contém o quanto a probabilidade de que o eleitor A escolha $i$ e não $j$ mudou com a variação na posição de $A$ de 3,25 para 7,75. Se um eleitor que está no ponto 3,25 na escala esquerda-direita tem uma probabilidade predita de votar para $i$ de 0,25, e um eleitor em 7,75 tem uma probabilidade de escolher $i$ de .65 , então a probabilidade da primeira diferença seria 0,40. O escore por país é a média dos três escores calculados para os pares de partidos para aquele país ${ }^{15}$.

As diferenças entre os países no que se refere ao voto ideológico são enormes. Tal como se esperava, a capacidade preditiva do voto com base na posição esquerda-direita é maior em países com volatilidade eleitoral mais baixa. A correlação entre essa volatilidade e a média das probabilidades da primeira diferença na Tabela 2 é $-0,56$ ( $n=32$, significante em $p<0,001)$. Essa forte correlação entre o voto ideológico e a estabilidade da competição interpartidária sugere que as três abordagens teóricas discutidas antes estavam provavelmente corretas ao sustentar que os vínculos programáticos/ideológicos são o modo principal de construir um sistema partidário institucionalizado. Não obstante, em alguns casos (Estados Unidos e Austrália, por exemplo), a estabilidade eleitoral é muito alta a despeito da moderada estruturação ideológica do voto, enquanto alguns países pós-comunistas (República Tcheca e Bulgária) exibem de moderada à alta volatilidade eleitoral, apesar da alta estruturação ideológica. A enorme variação do voto ideológico apóia fortemente nosso argumento de que os cientistas sociais não podem pressupor que a competição partidária é programática ou ideológica. Essa pressuposição é enganadora na maioria dos sistemas partidários fluidos.

\footnotetext{
15 Calculamos coeficientes que não eram significativos no nível de $p<0,10$ como igual a 0 porque eles não se distinguem estatisticamente de 0 nesse nível.
} 


\section{Tabela 2}

\section{Voto ideológico em 33 países}

(Variável dependente para as colunas 2 a 5: voto partidário expresso pelos respondentes Variável independente: posição esquerda-direita dos respondentes em uma escala de 1 a 10)

\begin{tabular}{|c|c|c|c|c|c|}
\hline País & $\begin{array}{c}\text { Par de partidos } \\
\text { (variável dependente) }\end{array}$ & $\begin{array}{l}\text { Significância do } \\
\text { coeficiente } \\
\text { logístico } \\
\text { esquerda-direita }\end{array}$ & $\begin{array}{l}\text { Nagelkerke } \\
\mathbf{R}^{2}\end{array}$ & $\begin{array}{c}\text { Probabilidades da } \\
\text { primeira diferença } \\
\text { entre os valores } \\
\text { esquerda-direita } \\
3,25 \text { e } 7,75\end{array}$ & $\begin{array}{c}\text { Média das } \\
\text { probabilidades } \\
\text { da primeira } \\
\text { diferença * }\end{array}$ \\
\hline \multirow{3}{*}{ Itália } & Forza Italia v. PDS & 0,000 & 0,85 & 0,93 & \multirow{3}{*}{0,72} \\
\hline & Forza Italia v. AN & 0,000 & 0,13 & 0,25 & \\
\hline & PDS v. AN & 0,000 & 0,91 & 0,98 & \\
\hline \multirow{3}{*}{ Suécia } & Moderata Samligspartiet v. Social Democrata & 0,000 & 0,82 & 0,93 & \multirow{3}{*}{0,69} \\
\hline & Moderata Samligspartiet v. Vansterpartiet & 0,000 & 0,94 & 0,91 & \\
\hline & Social Democrata v. Vansterpartiet & 0,000 & 0,23 & 0,24 & \\
\hline \multirow{3}{*}{ Portugal } & PSD v. PS & 0,000 & 0,50 & 0,88 & \multirow{3}{*}{0,64} \\
\hline & PSD v. CDU & 0,000 & 0,82 & 0,80 & \\
\hline & CDU v. PS & 0,000 & 0,47 & 0,25 & \\
\hline \multirow{3}{*}{$\begin{array}{l}\text { República } \\
\text { Tcheca }\end{array}$} & ODS v. CSSD & 0,000 & 0,62 & 0,82 & \multirow{3}{*}{0,62} \\
\hline & ODS v. KCSM & 0,000 & 0,89 & 0,82 & \\
\hline & CSSD v. KCSM & 0,000 & 0,52 & 0,22 & \\
\hline \multirow{3}{*}{ Holanda } & PvdA v. CDA & 0,000 & 0,47 & 0,75 & \multirow{3}{*}{0,60} \\
\hline & PvdA v. D'66 & 0,000 & 0,11 & 0,40 & \\
\hline & CDA v. D'66 & 0,000 & 0,28 & 0,65 & \\
\hline \multirow{3}{*}{ Chile } & Socialistas (PS+PPD) v. PDC & 0,000 & 0,12 & 0,40 & \multirow{3}{*}{0,56} \\
\hline & Conservadores (UDI+RN) v. PDC & 0,000 & 0,33 & 0,54 & \\
\hline & Conservadores v. Socialistas & 0,000 & 0,53 & 0,73 & \\
\hline \multirow{3}{*}{ Uruguai } & Colorado v. Nacional & 0,066 & 0,01 & 0,13 & \multirow{3}{*}{0,56} \\
\hline & Colorado v. Frente Amplio & 0,000 & 0,62 & 0,77 & \\
\hline & Nacional v. Frente Amplio & 0,000 & 0,58 & 0,79 & \\
\hline \multirow{3}{*}{ Espanha } & PP v. PSOE & 0,000 & 0,63 & 0,80 & \multirow{3}{*}{0,55} \\
\hline & PP v. Izquierda Unida & 0,000 & 0,62 & 0,85 & \\
\hline & PSOE v. IU & Não significante & 0,00 & - & \\
\hline \multirow{3}{*}{ França } & Socialista v. RPR & 0,000 & 0,76 & 0,92 & \multirow{3}{*}{0,54} \\
\hline & Socialista v. Front Nacional & 0,000 & 0,59 & 0,71 & \\
\hline & RPR v. Front Nacional & Não significante & 0,01 & - & \\
\hline \multirow{3}{*}{ Polônia } & Solidarnosc v. PSL & 0,000 & 0,18 & 0,39 & \multirow{3}{*}{0,52} \\
\hline & Solidarnosc v. SLD & 0,000 & 0,53 & 0,66 & \\
\hline & PSL v. SLD & 0,000 & 0,24 & 0,50 & \\
\hline \multirow{3}{*}{ Reino Unido } & Conservador v. Trabalhista & 0,000 & 0,43 & 0,73 & \multirow{3}{*}{0,52} \\
\hline & Conservador v. Liberal Democrata & 0,000 & 0,21 & 0,52 & \\
\hline & Trabalhista v. Liberal Democrata & 0,000 & 0,07 & 0,32 & \\
\hline & SPD v. CDU/CSU & 0,000 & 0,35 & 0,71 & \\
\hline Ocidental & SPD v. Greens & 0,010 & 0,03 & 0,13 & 0,51 \\
\hline & CDU/CSU v. Greens & 0,000 & 0,47 & 0,69 & \\
\hline & Socialdemokr. v. Konservative & 0,000 & 0,52 & 0,77 & \\
\hline Dinamarca & Socialdemokr v. Venstre & 0,000 & 0,52 & 0,74 & 0,50 \\
\hline & Konservative v. Venstre & Não significante & 0,00 & - & \\
\hline & Pasok v. Nea Demokratia & 0,000 & 0,70 & 0,82 & \\
\hline Grécia & PASOK v. Politiki Anixi & 0,000 & 0,18 & 0,28 & 0,50 \\
\hline & Nea Demokratia v. Pol.Anixi & 0,000 & 0,17 & 0,40 & \\
\hline & Radical Démocratique v. Socialista & 0,000 & 0,40 & 0,70 & \\
\hline Suíça & Radical Démocratique v. Democracia Cristã & Não significante & 0,01 & - & 0,48 \\
\hline & Socialist v. Democracia Cristã & 0,055 & 0,46 & 0,73 & \\
\hline & União das Forças Democ. v. Socialistas & 0,000 & 0,63 & 0,67 & \\
\hline Bulgária & União das Forças Democ. v. Partido Agrário & 0,000 & 0,28 & 0,47 & 0,45 \\
\hline & Socialistas v. Partido Agrário & 0,000 & 0,22 & 0,20 & \\
\hline
\end{tabular}


MAINWARING, S.;TORCAL, M. Teoria e institucionalização dos sistemas partidários...

\begin{tabular}{|c|c|c|c|c|c|}
\hline País & $\begin{array}{c}\text { Par de partidos } \\
\text { (variável dependente) }\end{array}$ & $\begin{array}{l}\text { Significância do } \\
\text { coeficiente } \\
\text { logístico } \\
\text { esquerda-direita }\end{array}$ & $\begin{array}{c}\text { Nagelkerke } \\
R^{2}\end{array}$ & $\begin{array}{c}\text { Probabilidades da } \\
\text { primeira diferença } \\
\text { entre os valores } \\
\text { esquerda-direita } \\
3,25 \text { e } 7,75\end{array}$ & $\begin{array}{l}\text { Média das } \\
\text { probabilidades } \\
\text { da primeira } \\
\text { diferença * }^{*}\end{array}$ \\
\hline \multirow{3}{*}{ Noruega } & Trabalhista v. Progressista & 0,000 & 0,10 & 0,28 & \multirow{3}{*}{0,43} \\
\hline & Trabalhista v. Conservador & 0,000 & 0,38 & 0,59 & \\
\hline & Progressista v. Conservador & 0,000 & 0,10 & 0,42 & \\
\hline Estados Unidos & Republicanos v. Democratas & 0,000 & 0,15 & 0,42 & 0,42 \\
\hline \multirow{3}{*}{ Japão } & Liberal Democrata v. Partido Nova Fronteira & 0,000 & 0,11 & 0,25 & \multirow{3}{*}{0,38} \\
\hline & Liberal Democrata v. Socialista & 0,000 & 0,30 & 0,53 & \\
\hline & Partido Nova Fronteira v. Socialista & 0,009 & 0,08 & 0,35 & \\
\hline \multirow{3}{*}{ Bélgica } & CD\&V v. PS & 0,000 & 0,49 & 0,34 & \multirow{3}{*}{0,36} \\
\hline & CD\&V v. VLD & Não significante & 0,01 & - & \\
\hline & PS v. VLD & 0,000 & 0,48 & 0,73 & \\
\hline \multirow{3}{*}{ Eslovênia } & Liberal Democracia v. Partido do Povo & 0,002 & 0,06 & 0,31 & \multirow{3}{*}{0,36} \\
\hline & Liberal Democracia v. Democracia Cristã & 0,000 & 0,20 & 0,55 & \\
\hline & Partido do Povo v. Democracia Cristã & 0,032 & 0,04 & 0,21 & \\
\hline \multirow{3}{*}{ Hungria } & MSZP v. FIDESZ & 0,000 & 0,32 & 0,57 & \multirow{3}{*}{0,31} \\
\hline & MSZP v. FKGP & 0,010 & 0,04 & 0,12 & \\
\hline & FIDESZ v. FKGP & 0,000 & 0,14 & 0,23 & \\
\hline \multirow{3}{*}{ Austrália } & Trabalhista v. Liberal & 0,000 & 0,16 & 0,45 & \multirow{3}{*}{0,30} \\
\hline & Trabalhista v. Verde & 0,006 & 0,01 & 0,05 & \\
\hline & Liberal v. Verde & 0,000 & 0,17 & 0,39 & \\
\hline \multirow{3}{*}{ Argentina } & PJ v. UCR & 0,000 & 0,05 & 0,22 & \multirow{3}{*}{0,26} \\
\hline & PJ v. Frepaso & 0,000 & 0,13 & 0,37 & \\
\hline & UCR v. Frepaso & 0,034 & 0,03 & 0,18 & \\
\hline \multirow{3}{*}{ Taiwan } & Nacionalista v. Democracia Progressista & 0,000 & 0,13 & 0,41 & \multirow{3}{*}{0,25} \\
\hline & Nacionalista v. Partido Novo & 0,005 & 0,02 & 0,13 & \\
\hline & Democracia Progressista v. Partido Novo & 0,002 & 0,05 & 0,22 & \\
\hline \multirow{3}{*}{ México } & PRI v. PRD & 0,000 & 0,13 & 0,28 & \multirow{3}{*}{0,20} \\
\hline & PAN v. PRD & 0,000 & 0,04 & 0,18 & \\
\hline & PRI v. PAN & 0,000 & 0,03 & 0,13 & \\
\hline \multirow{3}{*}{ Venezuela } & AD v. COPEI & Não significante & 0,00 & - & \multirow{3}{*}{0,19} \\
\hline & $A D$ v. Causa $R$ & 0,000 & 0,22 & 0,28 & \\
\hline & COPEI v. Causa $R$ & 0,000 & 0,21 & 0,29 & \\
\hline \multirow{3}{*}{ Brasil } & PMDB v. PT & 0,000 & 0,08 & 0,22 & \\
\hline & PMDB v. PSDB & 0,064 & 0,02 & 0,12 & 0,18 \\
\hline & PT v. PSDB & 0,000 & 0,15 & 0,19 & \\
\hline & Democrata v. Comunista & Não significante & 0,02 & - & \\
\hline Ucrânia & Democrata v. Movimento Popular & 0,000 & 0,13 & 0,30 & 0,15 \\
\hline & Comunista v. Movimento Popular & 0,007 & 0,04 & 0,16 & \\
\hline & Comunista v. Russia Nosso Lar & 0,000 & 0,10 & 0,28 & \\
\hline Rússia & Comunista v. Liberal Democracia & 0,040 & 0,03 & 0,08 & 0,12 \\
\hline & Russia Nosso Lar v. Liberal Democr. & Não significante & 0,01 & - & \\
\hline & Cambio 90 v. UPP & Não significante & 0,00 & - & \\
\hline Peru & Cambio 90 v. APRA & Não significante & 0,00 & - & 0,06 \\
\hline & UPP v. APRA & 0,015 & 0,03 & 0,18 & \\
\hline & CDR v. PDSR & 0,001 & 0,03 & 0,18 & \\
\hline Romênia & CDR v. PD & Não significante & 0,01 & - & 0,06 \\
\hline & PDSR v. PD & Não significante & 0,01 & - & \\
\hline & Congresso Nacional Indiano v. BJP & 0,023 & 0,02 & 0,08 & \\
\hline Índia & Congresso Nac. Indiano v. Partido do Povo & Não significante & 0,01 & - & 0,05 \\
\hline & BJP v. Partido do Povo & 0,024 & 0,02 & 0,08 & \\
\hline
\end{tabular}

* A coluna 6 é a média dos três escores da coluna 5, contando os coeficientes não significativos no nível de $p<0,10$ (coluna 3) como iguais a 0 na coluna 5.

Fontes: European Election Study 1994 (Bélgica, Dinamarca, França, Grécia, Itália, Holanda, Portugal, Reino Unido, Alemanha Ocidental), Comparative Study of Electoral Systems 1996-2000 (República Tcheca, Hungria, Romênia), World Values Survey 1997 (outros países). 
Esperávamos que, onde a ancoragem programática/ideológica dos partidos fosse mais fraca, aqueles que apóiam partidos teriam distribuições mais espalhadas ao longo da escala esquerda-direita, pois fortes vínculos dessa natureza a partidos dependem da consistência programática/ ideológica dos eleitores leais aos partidos. Para testar essa hipótese, a Tabela 3 apresenta uma medida do grau em que os partidos de um país eram coesos ao longo da dimensão esquerda-direita. Construímos o escore do país começando com o desvio-padrão dos que apóiam cada partido ao longo da dimensão esquerda-direita, depois ponderamos os partidos pelo seu número de apoiadores ${ }^{16}$. A correlação entre a ancoragem ideológica de um país na Tabela 2 e seu desvio padrão ponderado na Tabela 3 é 0,50 , significativo no nível de $p<0,01(n=30)$. Essa correlação sustenta a hipótese de que a consistência programática/ideológica entre os partidos facilita a estruturação ideológica da competição partidária.

Embora as vinculações programáticas ou ideológicas entre eleitores e partidos não sejam a única maneira de criar estabilidade no sistema partidário, elas são um meio importante pelo qual os eleitores se tornam ligados a partidos e, portanto, um meio importante para que os partidos se enraízem na sociedade. Onde os vínculos ideológicos a partidos são fortes, a volatilidade eleitoral tende a ser menor, exatamente como Lipset e Rokkan (1967) e os teóricos espaciais postulam ${ }^{17}$. Onde há uma vinculação fraca entre a posição programática e ideológica dos eleitores e seu partido preferido, é mais provável que os eleitores tendam a mudar de um partido para outro; ou seja, que sejam eleitores flutuantes.

\footnotetext{
16 Ver Inglehart e Klingemann (1976), Tabela 13.3 para dados comparáveis sobre desvios padrões de partidários na Europa Ocidental em 1973. A Irlanda era um outlier, com uma relação tênue entre autolocalização esquerda-direita e preferência partidária.

17 Com fraco voto ideológico, mas padrões eleitorais muito estáveis, os Estados Unidos constituem uma notável exceção a essa generalização. A exceção americana mostra que os vínculos programáticos/ideológicos não são o único caminho para ter sistemas partidários estáveis. As altas barreiras de entrada para os novos partidos ajudam a explicar a anomalia norte-americana. Elas ajudam a possibilitar que republicanos e democratas dominem o mercado eleitoral, apesar da modesta estruturação ideológica.
} 
MAINWARING, S.;TORCAL, M. Teoria e institucionalização dos sistemas partidários...

Tabela 3

Desvio-padrão das posições esquerda-direita dos eleitores que apóiam partidos

\begin{tabular}{|c|c|c|c|}
\hline País & Escore do país* & País & Escore do país * \\
\hline Suécia & 1,35 & Ucrânia & 1,77 \\
\hline Alemanha Ocidental & 1,46 & Japão & 1,83 \\
\hline Espanha & 1,46 & Estados Unidos & 1,83 \\
\hline Portugal & 1,48 & Argentina & 1,85 \\
\hline Itália & 1,49 & Rússia & 1,86 \\
\hline Holanda & 1,49 & Bulgária & 1,87 \\
\hline França (94) & 1,50 & Uruguai & 1,88 \\
\hline Noruega & 1,51 & Hungria & 1,90 \\
\hline Dinamarca & 1,55 & Bélgica & 1,93 \\
\hline Grécia & 1,56 & Polônia & 1,98 \\
\hline $\begin{array}{l}\text { Reino Unido (não inclui } \\
\text { Irlanda do Norte) }\end{array}$ & 1,64 & Peru & 2,10 \\
\hline Eslovênia & 1,65 & México & 2,45 \\
\hline Suíça & 1,65 & Índia & 2,52 \\
\hline República Tcheca & 1,67 & Romênia & 2,59 \\
\hline Taiwan & 1,67 & Brasil & 2,84 \\
\hline Austrália & 1,68 & Venezuela & 3,00 \\
\hline Chile & 1,68 & & \\
\hline
\end{tabular}

* A média ponderada do país é o desvio-padrão médio para todos os partidos com pelo menos dois apoiadores, ponderado pelo número de apoiadores dos partidos. A ponderação significa que todos os indivíduos que expressaram uma preferência partidária são ponderados igualmente, uma vez que seus partidos têm pelo menos um outro apoiador entre os respondentes. O motivo para excluir partidos com apenas um apoiador é que o desvio-padrão deve ser zero se $\mathrm{N}=1$.

Fontes: European Election Study 1994 (Bélgica, Dinamarca, França, Grécia, Itália, Holanda, Portugal, Reino Unido, Alemanha Ocidental), Comparative Study of Electoral Systems 1996-2000 (República Tcheca, Hungria, Romênia), World Values Survey 1995-1997 (outros países).

Esses resultados indicam a necessidade de repensar as teorias sobre eleitores, voto e competição partidária em sistemas partidários menos institucionalizados. Os modelos espaciais e outras abordagens teóricas que pressupõem o voto ideológico não estão errados, mas há uma considerável variação na acuidade de seu retrato da competição partidária em diferentes países - fato que os modelos espaciais não reconheceram. O voto ideológico é um aspecto poderoso da competição partidária na maioria das democracias industriais avançadas, mas é muito mais fraco na maioria dos regimes competitivos pós-1978. Por implicação, alguns dos instrumentos teóricos e dos pressupostos que foram essenciais na compreensão da competição partidária nas democracias industriais avançadas são menos úteis - e às vezes até problemáticos - na análise dos sistemas partidários menos institucionalizados. 
A correlação modesta entre a estruturação ideológica da competição partidária e a estabilidade eleitoral sugere outro ponto fundamental. Todas as três teorias discutidas nesta seção passam por cima ou não valorizam suficientemente três vínculos não-programáticos e não-ideológicos que podem orientar os eleitores (KITSCHELT, 2000), embora somente dois dos três possam criar laços estáveis entre eleitores e partidos e, portanto, promover um maior enraizamento partidário na sociedade. Essas rationales não-programáticas merecem muita atenção em sistemas partidários menos institucionalizados. Primeiro, os eleitores podem escolher baseados mais em bens clientelistas do que em posição ideológica. Nesse caso, um eleitor pode optar por um político ou partido, mesmo que seu concorrente esteja ideologicamente mais próximo de sua posição preferida. Ao assegurar bens clientelistas, os eleitores podem defender seus interesses materiais de uma maneira que não seria possível por meio de bens públicos ${ }^{18}$. Em segundo lugar, todas as três teorias não levam em conta que o voto pode ser personalista, sem um vínculo forte com preferências ideológicas ou com localização sociológica (SILVEIRA, 1998). O eleitor pode votar não por preferência ideológica, mas por simpatia pelos traços de personalidade de um candidato. Nessas condições, o laço ideológico entre indivíduos e partidos é fraco e pode não haver outro laço que crie uma fidelidade duradoura a determinado partido. Em terceiro lugar, os eleitores podem se ligar a partidos com base em laços tradicionais/afetivos, de alguma forma independentemente de clientelismo ou predileções programáticas. No entanto, nos regimes competitivos contemporâneos, em que a televisão tem um forte impacto na política, os vínculos tradicionais/afetivos quase certamente se desfarão.

\section{Raízes partidárias e voto personalista}

Nesta seção, examinamos um aspecto diferente das raízes dos partidos na sociedade. A disseminação do voto baseado nas características pessoais dos candidatos, sem conteúdo programático ou ideológico, é um sinal revelador da fraqueza das raízes partidárias. Quando há laços fortes entre eleitores e partidos, sejam construídos por vínculos programáticos/ideológicos, clientelistas ou tradicionais/afetivos, os eleitores permanecem fiéis ao seu partido e a personalidade dos candidatos tem importância secundária.

\footnotetext{
18 Não temos dados que nos permitam comparar o grau de voto clientelista em diferentes países. Indícios consideráveis - embora não sistemáticos - sugerem que o clientelismo é mais disseminado na maioria das democracias das terceira e quarta ondas do que nas democracias industriais avançadas. Ver Ames, 2001; Guevara Mann, 2001; Hagopian, 1996; Hartlyn, 1988, p. 170-183; Legg e Lemarchand, 1972; Mainwaring, 1999, p. 175-218; O'Donnell, 1996; Scott, 1972; e Stokes, no prelo.
} 
MAINWARING, S.;TORCAL, M. Teoria e institucionalização dos sistemas partidários...

Líderes e personalização tornaram-se cada vez mais importantes em resultados de eleições, mesmo em países com sistemas de governo parlamentaristas, constituindo o fenômeno chamado de "presidencialização das campanhas eleitorais modernas" (CREWE e KING, 1994; KAASE, 1994). Nas democracias industriais avançadas, a avaliação dos líderes pelos cidadãos contém componentes programáticos, ideológicos ou de identificação partidária. Nos sistemas partidários fluidos, o personalismo desprovido de componentes programáticos e ideológicos desempenha usualmente um papel muito maior no voto (SILVEIRA, 1998) ${ }^{19}$. Em sistemas mais institucionalizados, é mais provável que os eleitores se identifiquem com um partido, e os partidos dominam os padrões de recrutamento e deliberação política. Em sistemas fluidos, muitos eleitores escolhem mais de acordo com a personalidade do que com o partido, políticos antipartidos têm mais chance de ganhar eleições e o populismo e a antipolítica são mais comuns. A cena política é dominada mais por personalidades do que por partidos.

O voto personalista é um fenômeno político importante e parcialmente mensurável (KING, 2002a e 2002b), mas tem sido negligenciado na maior parte da literatura sobre voto, inclusive nos modelos espaciais e nos trabalhos baseados no esquema esquerda-direita. Em sistemas fluidos, personalidades independentes de partidos e preferências programáticas têm um impacto considerável nas campanhas eleitorais e políticos independentes podem ter sucesso em suas candidaturas a altos cargos. O espaço para os populistas é maior, especialmente nos sistemas presidencialistas, uma vez que os candidatos apelam diretamente aos eleitores, sem necessidade de se elegerem presidentes de partidos para se tornarem chefes de Estado.

Um modo de avaliar a importância do personalismo em campanhas eleitorais são os dados sobre os candidatos outsiders à presidência. Candidatos a presidente eleitoralmente competitivos, sejam independentes ou de partidos novos, refletem um alto grau de personalismo e a abertura dos eleitores para candidaturas externas aos partidos estabelecidos. Por motivos operacionais, definimos esses candidatos outsiders como independentes (sem filiação partidária) ou que pertencem a um partido que obteve menos de 5\% dos votos para a câmara baixa na eleição anterior e não apresentaram candidatura à presidência em qualquer eleição antes da anterior.

\footnotetext{
19 Silveira (1998) realiza um excelente estudo do voto personalista no Brasil. Ele enfatiza os aspectos não-programáticos e não-ideológicos dos eleitores brasileiros pobres. Esse tema tem ressonâncias em alguns trabalhos sobre os Estados Unidos (CONVERSE, 1964; HIBBING e THEISS-MORSE, 2002), mas vai no sentido oposto da maior parte do trabalho recente sobre as democracias industriais avançadas. $A$ literatura sobre populismo é relevante para a análise do voto personalista, dado que os líderes populistas estabelecem uma relação direta e personalista com as massas. Ver Roberts, 1995; Weffort, 1978; e Weyland, 1999.
} 
A Tabela 4 apresenta os dados sobre a fatia do voto ganho por candidatos presidenciais outsiders em seis países latino-americanos e (para comparação) nos Estados Unidos ${ }^{20}$. Os outsiders ganharam a eleição presidencial no Peru em 1990, na Venezuela em 1993 e 1998 e na Colômbia e no Equador em 2002 21. A recorrência extraordinária desses eventos políticos revela a fraca institucionalização do sistema partidário existente. Outro outsider (Evo Morales) foi para o segundo turno na eleição presidencial da Bolívia em 2002. Na Colômbia, na Venezuela, no Equador e na Bolívia, os outsiders obtiveram pelo menos $50 \%$ dos votos válidos em uma das duas últimas eleições presidenciais.

\section{Tabela 4}

\section{Porcentagem média do voto obtida por candidatos presidenciais outsiders nas cinco eleições presidenciais mais recentes, em países selecionados}

\begin{tabular}{|l|c|c|c|}
\hline \multicolumn{1}{|c|}{ País } & $\begin{array}{c}\text { Eleições } \\
\text { incluídas }\end{array}$ & $\begin{array}{c}\text { \% de voto obtido por } \\
\text { candidato outsider } \\
\text { eleição mais recente }\end{array}$ & $\begin{array}{c}\text { \% média do voto obtido por } \\
\text { candidatos outsiders } \\
\text { cinco últimas eleições }\end{array}$ \\
\hline Estados Unidos & $1984-2000$ & 0,3 & 6,0 \\
\hline Brasil* $^{*}$ & $1989-2002$ & 0,0 & 13,4 \\
\hline Equador & $1988-2002$ & 58,9 & 17,5 \\
\hline Bolívia & $1985-2002$ & 51,3 & 22,1 \\
\hline Venezuela & $1983-2000$ & 40,2 & 26,5 \\
\hline Colômbia & $1986-2002$ & 66,5 & 28,5 \\
\hline Peru & $1985-2001$ & 27,9 & 32,7 \\
\hline
\end{tabular}

* Os dados para o Brasil incluem somente quatro eleições porque houve apenas quatro eleições presidenciais populares desde a transição para a democracia em 1985.

20 Alguns detalhes adicionais sobre como codificamos os candidatos outsiders ou não: nossa intenção é levar em conta somente os partidos que são realmente novos. Portanto, se um partido mudou de nome da Eleição $t$ para a Eleição $t+1$, não o consideramos como partido novo em $t+1$. Pela mesma razão, não contamos uma aliança (coalizão) de partidos anteriormente existentes como um novo partido. Não contamos a fusão de dois partidos anteriormente existentes como um partido novo. Em casos de cisão de um partido, nenhum dos partidos resultantes foi contado como novo. Contamos como independentes os candidatos que não tinham uma filiação partidária. Dentre esses três pares de partidos, mostramos os resultados do par que teve o maior coeficiente estandardizado para a variável esquerda-direita. 0 voto mais claramente ideológico entre os três maiores pares de partidos nos diz mais sobre o voto ideológico do que uma média dos coeficientes estandardizados. Mesmo nos sistemas em que a ideologia é um aspecto poderoso da competição partidária, ela não é um preditor forte do voto entre cada e todos os pares de partidos. A ideologia deveria ser antes um bom preditor do voto entre partidos que são relativamente distantes ideologicamente. Se entre os três maiores partidos, dois são de centro-esquerda e o terceiro é de centro-direita, não esperaríamos que a ideologia fosse um preditor poderoso da preferência de voto entre os dois partidos de centro-esquerda.

21 Há dois tipos de outsiders: aqueles que jamais foram políticos nacionais e concorrem contra o establishment - como Alberto Fujimori, Hugo Chávez e Lucio Gutiérrez - e aqueles que estão fora do sistema partidário - como Rafael Caldera e Álvaro Uribe Vélez. Os primeiros não têm experiência anterior de política nacional e os últimos são dissidentes de partidos tradicionais. Aqui, nos concentramos nos políticos que estão fora do sistema partidário estabelecido. 
MAINWARING, S.;TORCAL, M. Teoria e institucionalização dos sistemas partidários...

No Brasil, o presidente Fernando Collor de Mello (1990-92) criou um partido com o objetivo de concorrer à presidência em 1989 e derrotou os candidatos dos partidos estabelecidos. Sete meses depois de sua posse, seu partido conquistou apenas 40 das 503 cadeiras da Câmara de Deputados nas eleições parlamentares de outubro de 1990. Com um claro apelo personalista e não partidário, seu partido desapareceu depois que ele renunciou em 1992, a fim de evitar o impeachment. 0 presidente peruano Alberto Fujimori (1990-2000) também criou um partido para concorrer à presidência, fez campanha contra os partidos e depois evitou esforços para construir um partido. No Peru, os políticos independentes dominaram as eleições municipais de 1995 e a possibilidade dos apelos antipartidários conquistarem o apoio popular levou ao surgimento de um novo grupo de políticos antipartidos. Fujimori controlava pessoalmente as escolhas de candidatos ao congresso em seu partido altamente personalizado (CONAGHAN, 2000) em um processo oposto ao que se encontra em um sistema institucionalizado. Além disso, é possível aos candidatos terem acesso às eleições sem um partido e vencê-las como independentes. $\mathrm{O}$ ex-líder golpista Hugo Chávez criou um partido novo em sua investida bem sucedida à presidência da Venezuela, em 1998. Do mesmo modo, no Equador, em 2002, o ex-líder golpista Lucio Gutiérrez criou um novo partido em sua campanha vencedora à presidência.

O personalismo e os políticos antipartidos são também comuns em alguns países pós-comunistas. 0 ex-presidente russo Boris léltsin não era membro de um partido e solapou os partidos. Alexander Lebed, que terminou em terceiro lugar na eleição presidencial da Rússia em 1996, concorreu como independente. Os candidatos não-partidários saíram-se bem nas eleições para as duas casas do parlamento russo. Nas eleições de 1993, bem mais da metade dos candidatos de distritos de um único representante à câmara baixa eram independentes sem filiação partidária, e somente 83 dos 218 deputados eleitos pertenciam a um partido (MOSER, 1995, p. 98). Em 1995, mais de mil dos 2.700 candidatos nessa categoria eram independentes. Dos 225 assentos destinados a representantes únicos, 78 foram ganhos por independentes; o maior partido conseguiu obter apenas 58 cadeiras (WHITE, ROSE e MCALLISTER, 1997, p. 203, 224). O ex-rei Simeão II da Bulgária também criou um veículo político personalista bem sucedido eleitoralmente.

Por quê o voto personalista é comum em alguns sistemas partidários, mesmo depois de um tempo considerável de regime democrático? Não podemos responder a essa questão plenamente aqui, mas é possível fazer algumas especulações. Primeiro, as seqüências históricas na construção dos partidos são importantes. Nas democracias antigas e bem estabelecidas, os partidos enraizaram-se na sociedade antes do surgimento dos meios modernos de 
comunicação de massa, em especial da televisão. Na Europa Ocidental, os partidos da classe operária integraram os trabalhadores no sistema político e proporcionaram fontes fundamentais de identidade (CHALMERS, 1964; PIZZORNO, 1981). Fenômeno semelhante ocorreu com os partidos democratas cristãos (KALYVAS, 1996). Em contraste, na maioria dos sistemas pouco institucionalizados, a televisão tornou-se um fenômeno de massa antes dos partidos estarem bem enraizados. Os candidatos a cargos executivos podem apresentar suas mensagens na televisão sem a necessidade de contar com organizações partidárias bem desenvolvidas (SARTORI, 1989), o que permite o surgimento de partidos altamente personalistas (GUNTHER e DIAMOND, 2003, p. 187). Em segundo lugar, o mau desempenho de muitos regimes competitivos pós-1978 desacreditou os partidos governantes (REMMER, 1991; ROBERTS e WIBBLES, 1999; TAVITS, 2005) e, até de uma maneira mais ampla, desacreditou os partidos como veículos de representação. Esse fenômeno abriu as portas para as cruzadas personalistas antipartidárias.

Em terceiro lugar, em muitos regimes competitivos pós-1978, os partidos são programaticamente difusos (KITSCHELT et al., 1999, p. 164-190; OSTINGUY, 1998), dificultando que os eleitores possam determinar qual deles está mais próximo de suas posições, ou então podem ser ideologicamente pouco confiáveis, fazendo mudanças radicais em seus posicionamentos (STOKES, 2001). Nessas circunstâncias, os eleitores são voláteis e é mais provável que se voltem para candidatos personalistas, que freqüentemente fazem campanha contra os partidos. Em quarto lugar, o voto personalista é provavelmente mais forte nos sistemas presidencialistas do que nos parlamentaristas e a maioria das democracias industriais avançadas possui sistemas desse último tipo, ao passo que muitos dos regimes competitivos pós-1978 são presidencialistas.

A predominância do personalismo está relacionada com a segunda e a quarta dimensões da institucionalização do sistema partidário. Os vínculos personalistas entre eleitores e candidatos tendem a ser mais fortes onde as raízes partidárias na sociedade são mais fracas. Em sistemas fluidos, os partidos possuem recursos precários e são pouco profissionalizados. Muitos partidos são veículos personalistas (CONAGHAN, 2000).

O voto baseado na avaliação racional de líderes poderia, em princípio, ser um sinal de sofisticação política e maior accountability eleitoral. King (2002a) chama tais avaliações, que têm conteúdo programático/ideológico, de efeitos indiretos das avaliações dos candidatos. Porém, em muitos sistemas partidários fluidos, a relação entre a posição ideológica dos indivíduos e sua avaliação dos líderes políticos é fraca pois essa avaliação não se baseia em princípios programáticos e ideológicos.

A Tabela 5 mostra a correlação produto-momento da avaliação dos indivíduos de líderes políticos e a posição deles na escala esquerda-direita. 
Tabela 5

Ancoragem ideológica da avaliação de líderes em 19 países incluídos no Conparative Study of Electoral Systems (coeficientes de correlação Pearson)

\begin{tabular}{|c|c|c|}
\hline $\begin{array}{c}\text { República Tcheca } \\
\text { (1996) }\end{array}$ & $\begin{array}{c}\text { Vaclav Klaus } \\
\text { Ellemann-Jensen } \\
\text { P. Stig Moeller }\end{array}$ & $\begin{array}{c}0,60^{* *} \\
-0,42^{* *} \\
-0,63^{* *}\end{array}$ \\
\hline \multicolumn{2}{|l|}{ Média } & 0,54 \\
\hline $\begin{array}{l}\text { Suécia } \\
\text { (1998) }\end{array}$ & $\begin{array}{l}\text { Goran Persson } \\
\text { Carl Bildt } \\
\text { Gudrun Schyman }\end{array}$ & $\begin{array}{c}-0,39^{* *} \\
0,58^{* *} \\
-0,48^{* *}\end{array}$ \\
\hline \multicolumn{2}{|l|}{ Média } & 0,48 \\
\hline Espanha & $\begin{array}{c}\text { Jose Maria Aznar } \\
\text { Joaquin Almunia } \\
\text { F. Frutos }\end{array}$ & $\begin{array}{c}0,57^{* *} \\
-0,32^{* *} \\
-0,29\end{array}$ \\
\hline \multicolumn{2}{|l|}{ Média } & 0,39 \\
\hline Austrália & $\begin{array}{c}\text { Paul Keating } \\
\text { John Howard } \\
\text { Tim Fischer }\end{array}$ & $\begin{array}{c}-0,33^{* *} \\
0,43^{\star *} \\
0,39^{\star *}\end{array}$ \\
\hline \multicolumn{2}{|l|}{ Média } & 0,38 \\
\hline $\begin{array}{c}\text { Dinamarca } \\
(1998)\end{array}$ & $\begin{array}{l}\text { P. Nyrup Rasmussen } \\
\text { Ellemann-Jensen } \\
\text { P. Stig Moeller }\end{array}$ & $\begin{array}{c}-0,36^{\star *} \\
0,52^{\star *} \\
0,26^{\star *}\end{array}$ \\
\hline \multicolumn{2}{|l|}{ Média } & 0,38 \\
\hline $\begin{array}{l}\text { Portugal } \\
(1997)\end{array}$ & $\begin{array}{l}\text { J. Barroso } \\
\text { A. Guterres } \\
\text { P. Portas }\end{array}$ & $\begin{array}{c}0,55^{\star *} \\
-0,24^{\star *} \\
0,35^{\star *}\end{array}$ \\
\hline \multicolumn{2}{|l|}{ Média } & 0,38 \\
\hline $\begin{array}{l}\text { Hungria } \\
(1998)\end{array}$ & $\begin{array}{c}\text { Gyula Horn } \\
\text { Viktor Orban } \\
\text { Jozsef Torgyan }\end{array}$ & $\begin{array}{c}-0,39^{\star *} \\
0,34^{\star *} \\
0,36^{\star *}\end{array}$ \\
\hline \multicolumn{2}{|l|}{ Média } & 0,36 \\
\hline $\begin{array}{l}\text { Noruega } \\
(1997)\end{array}$ & $\begin{array}{c}\text { Thorbjorn Jagland } \\
\text { Carl Ivar Hagen } \\
\text { Jan Petersen }\end{array}$ & $\begin{array}{c}-0,17^{* *} \\
0,45^{\star *} \\
0,40^{\star *}\end{array}$ \\
\hline \multicolumn{2}{|l|}{ Média } & 0,34 \\
\hline $\begin{array}{l}\text { Suíça } \\
\text { (1999) }\end{array}$ & $\begin{array}{l}\text { Christoph Blocher } \\
\text { Ruth Dreifuss } \\
\text { Franz Steinegger }\end{array}$ & $\begin{array}{c}0,50^{* *} \\
-0,34^{* *} \\
0,18^{* *}\end{array}$ \\
\hline \multicolumn{2}{|l|}{ Média } & 0,34 \\
\hline $\begin{array}{l}\text { Reino Unido } \\
\text { (1997) }\end{array}$ & $\begin{array}{c}\text { Tony Blair } \\
\text { John Major } \\
\text { Paddy Ashdown }\end{array}$ & $\begin{array}{c}-0,30^{* *} \\
0,40^{* *} \\
-0,16^{\star *}\end{array}$ \\
\hline \multicolumn{2}{|l|}{ Média } & 0,29 \\
\hline
\end{tabular}

\begin{tabular}{|c|c|c|}
\hline Estados Unidos & $\begin{array}{l}\text { Bill Clinton } \\
\text { Bob Dole }\end{array}$ & $\begin{array}{l}-0,27^{* *} \\
0,31^{* *}\end{array}$ \\
\hline \multicolumn{2}{|l|}{ Média } & 0,29 \\
\hline $\begin{array}{l}\text { Rússia } \\
(1999)\end{array}$ & $\begin{array}{l}\text { Zyuganov } \\
\text { Kiriyenko } \\
\text { Luzhkov }\end{array}$ & $\begin{array}{l}-0,51^{\text {** }} \\
0,18^{\star *} \\
-0,12^{\star *}\end{array}$ \\
\hline \multicolumn{2}{|l|}{ Média } & 0,27 \\
\hline $\begin{array}{c}\text { Alemanha } \\
(1998)\end{array}$ & $\begin{array}{c}\text { Schroeder } \\
\text { Kohl } \\
\text { Waigel }\end{array}$ & $\begin{array}{l}-0,21^{* *} \\
0,26^{\star *} \\
0,28^{* *}\end{array}$ \\
\hline \multicolumn{2}{|l|}{ Média } & 0,25 \\
\hline $\begin{array}{l}\text { Holanda } \\
(1998)\end{array}$ & $\begin{array}{c}\text { Wim Kok } \\
\text { Frits Bolkesetein } \\
\text { J. De Hoop }\end{array}$ & $\begin{array}{c}-0,10^{\star *} \\
0,34^{* *} \\
0,21^{* *}\end{array}$ \\
\hline \multicolumn{2}{|l|}{ Média } & 0,22 \\
\hline Eslovênia & $\begin{array}{c}\text { Janez Drnovsek } \\
\text { Marjan Podobnik } \\
\text { Janez Jansa }\end{array}$ & $\begin{array}{l}-0,19^{* *} \\
0,12^{\star *} \\
0,36^{\star *}\end{array}$ \\
\hline \multicolumn{2}{|l|}{ Média } & 0,22 \\
\hline Romênia & $\begin{array}{l}\text { Emil Constantinescu } \\
\text { Ion Iliescu }\end{array}$ & $\begin{array}{l}0,19^{* *} \\
-0,17^{* *}\end{array}$ \\
\hline \multicolumn{2}{|l|}{ Média } & 0,18 \\
\hline Taiwan & $\begin{array}{l}\text { Lee Tung-Hui } \\
\text { Peng Ming Min } \\
\text { Lin Yang-Gang }\end{array}$ & $\begin{array}{l}0,10^{*} \\
-0,02 \\
0,19^{\star *}\end{array}$ \\
\hline \multicolumn{2}{|l|}{ Média } & 0,10 \\
\hline $\begin{array}{l}\text { México } \\
(2000)\end{array}$ & $\begin{array}{c}\text { E. Zedillo } \\
\text { D. Fernandez de Cevallos } \\
\text { Cardenas Solorzano }\end{array}$ & $\begin{array}{l}0,12^{\star *} \\
0,11^{\star *} \\
-0,05\end{array}$ \\
\hline \multicolumn{2}{|l|}{ Média } & 0,08 \\
\hline Peru & $\begin{array}{l}\text { A. Toledo } \\
\text { A. Garcia } \\
\text { L. Flores }\end{array}$ & $\begin{array}{c}-0,05 \\
0,03 \\
0,13^{\star *} \\
\end{array}$ \\
\hline \multicolumn{2}{|l|}{ Média } & 0,04 \\
\hline
\end{tabular}

* Significante em 0,10; **Significante em 0,05

Os itens são escores de correlação Pearson entre a autodefinição ideológica esquerda-direita dos respondentes e a avaliação que fazem de líderes especificados. A média do país é uma média não-ponderada dos valores absolutos das três correlações individuais para o país. Correlações não-significantes não diferem estatisticamente de 0 no nível de confiança de $90 \%$ e, portanto, as tratamos como uma correlação de 0 ao calcular a média do país. 
A relação entre avaliação da liderança e ideologia é alta nas democracias industriais avançadas, mas baixa nos países com sistemas partidários pouco institucionalizados. Em alguns países (México, Peru e Taiwan), essa relação foi quase zero. A correlação entre a correlação média de Pearson dos países na Tabela 5 e sua volatilidade eleitoral é $0,41(n=18, p<0,10)$, demonstrando um vínculo um pouco mais forte entre posição ideológica e avaliação da liderança em sistemas partidários institucionalizados ${ }^{22}$.

A avaliação da liderança poderia ser, em princípio, um meio razoável de promover a representação e a accountability eleitoral, mas onde não está bem conectada a questões ideológicas ou programáticas, essa avaliação indica personalismo não-programático. De acordo com muitas visões (BARNES, 1977; CONVERSE e PIERCE, 1986), a representação desprovida de conteúdo programático não tem sentido; a representação só existe graças à correspondência programática/ideológica entre as idéias dos representantes e dos cidadãos (ver também LUNA e ZECHMEISTER, 2005). Essa representação ocorre somente por acaso, se é que acontece, quando não há relação entre as posições ideológicas dos cidadãos e a avaliação que fazem dos líderes políticos. Em muitos regimes competitivos pós-1978, a conexão entre a posição ideológica dos cidadãos e seus líderes políticos preferidos é fraca.

A importância do voto personalista desprovido de muito conteúdo ideológico em sistemas partidários menos institucionalizados sugere, mais uma vez, a necessidade de cautela na aplicação de modelos teóricos baseados no pressuposto de que a escolha eleitoral é programática ou ideológica. Com freqüência, não é este o caso em sistemas partidários fluidos.

\section{Conclusão}

A consciência da importância da institucionalização do sistema partidário aumentou na última década, mas os cientistas sociais que trabalham sobre sistemas fluidos precisam continuar a repensar o modo como teorizamos e comparamos os sistemas partidários. Algumas teorias que foram apresentadas como universais - por exemplo, as teorias espaciais do voto e da competição partidária - são, na verdade, mais úteis para analisar as democracias industriais avançadas do que os sistemas fluidos. É essencial estar consciente dessas diferenças entre os dois sistemas e evitar a pressuposição de que teorias supostamente universais, construídas implicitamente com base nas democracias industriais avançadas, serão aplicáveis a sistemas partidários fluidos. A análise de sistemas menos institucionalizados lança luz sobre questões importantes que não

\footnotetext{
22 Essa correlação é para os dezessete países incluídos em ambas as Tabelas 1 e 5.
} 
MAINWARING, S.;TORCAL, M. Teoria e institucionalização dos sistemas partidários...

aparecem quando se analisam as democracias industriais avançadas ${ }^{23}$.

Os sistemas partidários variam muito em níveis de institucionalização, e esta varia independentemente do número de partidos e do nível de polarização. Os analistas que comparam sistemas partidários com base no número de partidos põem no mesmo grupo os casos multipartidários, sem levar em conta o nível de institucionalização, mas os casos pouco institucionalizados diferem bastante daqueles solidamente enraizados. É enganoso tratar todos os sistemas multipartidários como uma categoria indiferenciada quando há enormes diferenças em institucionalização. Equador, Noruega, Peru, Rússia e Suécia possuem sistemas multipartidários, mas os da Noruega e da Suécia são muito mais institucionalizados do que os dos outros três países citados. Misturar indiscriminadamente esses casos de multipartidarismo esconde diferenças profundas na natureza dos sistemas.

A institucionalização varia também de modo significativo em relação à distância ideológica no sistema partidário. Alguns sistemas polarizados (por exemplo, a França dos anos 1960 aos anos 1980, a Itália dos anos 1940 aos 1980) estavam bem institucionalizados. Outros sistemas polarizados (o Brasil de meados a fins dos anos 1980, a Venezuela desde 1998) são menos institucionalizados e funcionam de maneira diferente. Uma questão fundamental no estudo comparativo de sistemas partidários, tanto quanto o número de partidos e a distância ideológica entre eles, é o seu nível de institucionalização.

Nosso foco neste artigo concentrou-se nas diferenças cruciais na institucionalização do sistema partidário e em como essas diferenças exigem que se repense a teoria do sistema partidário. Nossa intuição é de que a institucionalização tem conseqüências importantes para a política democrática. De outro modo, não seria uma questão essencial no estudo dos sistemas partidários. Desse modo, encerramos com duas observações sobre as conseqüências da fraca institucionalização do sistema.

Primeiro, a pouca institucionalização introduz mais incertezas quanto aos resultados eleitorais e pode enfraquecer os regimes democráticos. A transferência de votos de um partido para o outro é maior, as barreiras de entrada para novos partidos são mais baixas e a probabilidade de que políticos personalistas antisistema possam chegar à chefia do governo é muito maior. Essa incerteza revelouse inimiga da democracia até os anos 1980, quando o fim da Guerra Fria reduziu o nível do conflito político e facilitou a expansão pós-1989 das democracias e semidemocracias no mundo. Mas, mesmo no contexto do pós-Guerra Fria, o grau muito

\footnotetext{
23 Numa linha de argumentação semelhante, Mainwaring (2003) sustenta que os partidos em democracias menos institucionalizadas (a maioria dos casos pós-1978) têm objetivos diferentes dos partidos nas democracias industriais avançadas. Os primeiros estão preocupados com objetivos que envolvem o regime político (preservá-lo ou solapá-lo), além dos objetivos eleitorais e de política pública.
} 
mais alto de personalismo em sistemas partidários pouco institucionalizados pode abrir caminho para o autoritarismo (por exemplo, Fujimori no Peru em 1992) ou para uma erosão dos regimes democráticos e semidemocráticos (por exemplo, Hugo Chávez na Venezuela desde 1998) (MAYORGA, no prelo; TANAKA, no prelo).

Em segundo lugar, a institucionalização fraca é inimiga da accountability eleitoral. Na maioria das democracias, os partidos são o mecanismo primário dessa accountability e, para que esta funcione bem, os eleitores devem poder identificar em termos amplos - o que são os principais partidos e o que defendem (HINICH e MUNGER, 1994). Em contextos nos quais os partidos aparecem e desaparecem com freqüência, onde a competição entre eles é ideológica e programaticamente difusa e onde personalidades costumam ofuscar os partidos como rota para o poder executivo, as perspectivas de uma accountability eleitoral efetiva sofrem abalos consideráveis ${ }^{24}$.

Para que essa accountability e a representação política funcionem bem, o ambiente político precisa proporcionar aos cidadãos elementos efetivos de informação que Ihes possibilitem votar de forma racional, sem gastar tempo desmedido para chegar a essas decisões. Em sistemas institucionalizados, os partidos oferecem uma referência ideológica que dá certa ancoragem aos eleitores, reduzindo os custos da informação e aumentando assim os níveis de accountability eleitoral. A estabilidade limitada de sistemas partidários menos institucionalizados e o fraco conteúdo programático/ideológico que as siglas dos partidos oferecem nesses contextos reduzem os elementos informativos que esses sistemas oferecem aos eleitores, por sua vez, dificultando a racionalidade e diminuindo o potencial para uma accountability eleitoral baseada em uma avaliação racional de políticas, governos e líderes. Onde essa accountability sofre, pode romper-se a promessa da democracia representativa de que os políticos eleitos servirão de agentes dos eleitores para promover algum bem comum ou defender os interesses de eleitorados específicos (LUNA e ZECHMEISTER, 2005).

Em uma das citações mais famosas da história da análise dos partidos políticos, Schattschneider (1942, p. 1) escreveu que os "partidos políticos criaram a democracia moderna e a democracia moderna é impensável exceto em termos dos partidos". Se a história da democracia moderna está alicerçada sobre os partidos políticos, então podemos esperar que a democracia apresente algumas deficiências onde os partidos são mecanismos menos estáveis de representação, accountability e estruturação do que foram nas democracias industriais avançadas.

\footnotetext{
${ }^{24}$ A accountability eleitoral também sofre onde os partidos fazem mudanças radicais de orientação, como ocorreu em muitos países latino-americanos nos anos 1980 e 1990 (STOKES, 2001). Em alguns sistemas fluidos, um grande número de legisladores muda de partido durante seus mandatos (HELLER e MERSHON, 2005). Essa prática também enfraquece a accountability eleitoral.
} 


\section{Referências Bibliográficas}

ALCÁNTARA, M. La elite parlamentaria latinoamericana y el continuo izquierda-derecha. In: HOFMEISTER, W.; THESING, J. (ed.). Transformación de los sistemas políticos en América Latina. Buenos Aires: Konrad Adenauer, 1995.

AMES, B. The deadlock of democracy in Brazil. Ann Arbor: University of Michigan Press, 2001.

BARNES, S. H. Representation in Italy: institutionalized tradition and electoral choice. Chicago: The University of Chicago Press, 1977.

BARTOLINI, S.; MAIR, P. Identity, competition and electoral availability: the stabilization of european electorates, 1885-1985. Cambridge: Cambridge University Press, 1990.

BENDEL, P. Partidos políticos y sistemas de partidos en Centroamérica. In: NOHLEN, D. (ed.). Elecciones y sistemas de partidos en América Latina. San José: Instituto Interamericano de Derechos Humanos, 1993.

BIELASIAK, J. The institutionalization of electoral and party systems in postcommunist states. Comparative Politics, v. 34, n. 2, p. 189-210, 2002.

BUDGE, I. A new spatial theory of party competition: uncertainty, ideology and policy equilibria viewed comparatively and temporally. British Journal of Political Science, v. 24, n. 4, p. 443-467, 1994.

CHALMERS, D. The Social Democratic Party of Germany: from working class movement to modern political party. New Haven: Yale University Press, 1964.

CREWE, I.; KING, A. Are british elections becoming more 'presidential'?. In: JENNINGS, M. K.; MANN, T. E. (ed.). Elections at home and abroad: essays in honor of Warren E. Miller. Ann Arbor: University of Michigan Press, 1994.

CONAGHAN, C. M. The irrelevant right: Alberto Fujimori and the new politics of pragmatic Peru. In: MIDDLEBROOK, K. J. (ed.). Conservative parties, the right, and democracy in Latin America. Baltimore: Johns Hopkins University Press, 2000. 
CONVERSE, P. E. The nature of belief systems in mass publics. In: APTER, D. (ed.) Ideology and discontent. New York: The Free Press, 1964.

. Of time and stability. Comparative Political Studies, v. 2, n. 2, p. 139-171, 1969.

CONVERSE, P. E.; PIERCE, R. Political representation in France. Cambridge: Harvard University Press, 1986.

COPPEDGE, M. The dynamic diversity of latin american party systems. Party Politics, v. 4, n. 4, p. 547-568, 1998.

COX, G. Centripetal and centrifugal incentives in electoral systems. American Journal of Political Science, v. 34, n. 4, p. 903-935, 1990.

DALTON, R. J. Political parties and political representation: party supporters and party elites in nine nations. Comparative Political Studies, v. 18, n. 3, p. 276-299, 1985.

DALTON, R. J.; MCALLISTER, I.; WATTENBERG, M. The consequences of partisan dealignment. In: DALTON, R. J.; WATTENBERG, M. (ed.). Parties without partisans: political change in advanced industrial democracies. Oxford: Oxford University Press, 2000.

DIX, R. Democratization and the institutionalization of latin american political parties. Comparative Political Studies, v. 24, n. 1, p. 488-496, 1992.

DOWNS, A. An economic theory of democracy. New York: Harper and Row, 1957.

ENELOW, J.; HINICH, M. The spatial theory of voting: an introduction. Cambridge: Cambridge University Press, 1984.

FLEURY, C. J.; LEWIS-BECK, M. S. Anchoring the french voter: ideology versus party. The Journal of Politics, v. 55, n. 4, p. 1100-1109, 1993.

FIORINA, M. Retrospective voting in american national elections. New Haven: Yale University Press, 1981.

FUCHS, D.; KLINGEMANN, H. D. The left-right schema. In: JENNINGS, M. K. et al. Continuities in political action: a longitudinal study of political orientations in three western democracies. Berlin: Walter de Gruyter, 1990. 
MAINWARING, S.;TORCAL, M. Teoria e institucionalização dos sistemas partidários...

GRZYMALA-BUSSE, A. The effects of communist party transformation on the institutionalization of party systems. In: BOZÉKI, A.; ISHIYAMA, J. (ed.). The communist successor parties of Central and Eastern Europe. Armonk, NY: M. E. Sharpe, 2002.

GUEVARA MANN, C. Forsaken virtue: an analysis of the political behavior of panamanian legislators, 1984-1999. Ph.D. Thesis, University of Notre Dame, 2001.

GUNTHER, R. P.; HOPKIN, J. A crisis of institutionalization: the collapse of the UCD in Spain. In: GUNTHER, R. P.; MONTERO, J. R.; LINZ, J. J. (ed.). Political parties: old concepts and new challenges. Oxford: Oxford University Press, 2002.

GUNTHER, R.; DIAMOND, L. Species of political parties: a new typology. Party Politics, v. 9, n. 2, p. 167-199, 2003.

HAGOPIAN, F. Traditional politics and regime change in Brazil. New York: Cambridge University Press, 1996.

HARTLYN, J. The politics of coalition rule in Colombia. Cambridge: Cambridge University Press, 1988.

HELLER, W. B.; MERSHON, C. Party switching in the italian chamber of deputies. The Journal of Politics, v. 67, n. 2, p. 536-559, 2005.

HIBBING, J.; THEISS-MORSE, E. Stealth democracy: americans' beliefs about how government should work. Cambridge: Cambridge University Press, 2002.

HINICH, M.; MUNGER, M. Ideology and the theory of political choice. Ann Arbor: University of Michigan Press, 1994.

HUNTINGTON, S. Political order in changing societies. New Haven: Yale University Press, 1968.

The third wave: democratization in the late twentieth century. Norman: University of Oklahoma Press, 1991.

INGLEHART, R. The impact of values, cognitive level and social background. In: BARNES, S. H. et al. (ed.). Political action. Beverly Hills: Sage, 1979.

The changing structure of political cleavages in western society. In: DALTON, R. J.;

FLANAGAN, S.; BECK, P. (ed.). Electoral change in advanced industrial democracies: realignment or dealignment?. Princeton: Princeton University Press, 1984. 

1990.

Culture shift in advanced industrial democracy. Princeton: Princeton University Press,

INGLEHART, R.; KLINGEMANN, H. D. Party identification, ideological preference and the leftright dimension among western mass publics. In: BUDGE, I.; CREWE, I.; FARLIE, D. (ed.). Party identification and beyond: representations of voting and party competition. London: John Wiley and Sons, 1976.

IVERSEN, T. The logics of electoral politics: spatial, directional, and mobilizational effects. Comparative Political Studies, v. 27, n. 2, p. 155-189, 1994a.

Political leadership and representation in west european democracies: a test of three models of voting. American Journal of Political Science, v. 38, n. 1, p. 45-74, 1994b.

JANDA, K. Political parties: a cross national survey. New York: Free Press, 1980.

JOHNSON, E. P. Streams of least resistance: the institutionalization of political parties and democracy in Indonesia. Ph.D. Thesis, University of Virginia, 2002.

KAASE, M. Is there personalization in politics? Candidates and voting behavior in Germany. International Political Science Review, v. 15, p. 211-230, 1994.

KALYVAS, S. N. The rise of christian democracy in Western Europe. Ithaca: Cornell University Press, 1996.

KIEWET, R. D.; KINDER, D. Economic discontent and political behavior: the role of personal grievances and collective economic judgments in congressional voting. American Journal of Political Science, v. 23, n. 3, p. 495-527, 1979.

KING, A. Do leaders' personalities really matter?. In: KING, A. (ed.). Leaders' personalities and the outcomes of democratic elections. Oxford: Oxford University Press, 2002a.

Conclusions and implications. In: KING, A. (ed.). Leaders' personalities and the outcomes of democratic elections. Oxford: Oxford University Press, 2002b.

KITSCHELT, H. The transformation of european social democracy. Cambridge: Cambridge University Press, 1994. 
MAINWARING, S.;TORCAL, M. Teoria e institucionalização dos sistemas partidários...

Linkages between citizens and politicians in democratic politics. Comparative Political Studies, v. 33, n. 6/7, p. 845-879, 2000.

Party competition in Latin America and post-communist Eastern Europe: divergence of patterns, similarity of explanatory variables. Filadélfia, 27-31 de agosto, 2003. Trabalho apresentado na $100^{a}$ Reunião Anual da American Political Science Association.

KITSCHELT, H. et al. Post-communist party systems: competition, representation, and inter-party competition. Cambridge: Cambridge University Press, 1999.

KLINGEMANN, H. D. Measuring ideological conceptualizations. In: BARNES, S. H. et al. (ed.). Political action. Beverly Hills: Sage, 1979.

KNUTSEN, O. The partisan and value based component of the left-right self-placement: comparative study. International Political Science Review, v. 18, n. 2, p. 191-225, 1997.

KUENZI, M.; LAMBRIGHT, G. Party system institutionalization in 30 african countries. Party Politics, v. 7, n. 4, p. 437-468, 2001.

LAPONCE, J. A. Left and right: the topography of political perceptions. Toronto: University of Toronto Press, 1981.

LEGG, K.; LEMARCHAND, R. Political clientelism and development: a preliminary analysis. Comparative Politics, v. 4, n. 2, p. 149-178, 1972.

LEVITSKY, S. Transforming labor-based parties in Latin America: argentine peronism in comparative perspective. Cambridge: Cambridge University Press, 2003.

LIPSET, S. M.; ROKKAN, S. Cleavage structures, party systems, and voter alignments: an introduction. In: LIPSET, S. M.; ROKKAN, S. (ed.). Party systems and voter alignments: crossnational perspectives. New York: Free Press, 1967.

LUNA, J. P.; ZECHMEISTER, E. J. Political representation in Latin America: a study of elitemass congruence in nine countries. Comparative Political Studies, v. 38, n. 4, p. 388.416, 2005.

MAINWARING, S. Rethinking party systems in the third wave of democratization: the case of Brazil. Stanford, CA: Stanford University Press, 1999. 
. Party objectives in contexts of authoritarianism or fragile democracy: a dual game. In: MAINWARING, S.; SCULLY, T. R. (ed.). Christian democracy in Latin America: electoral competition and regime conflicts. Stanford: Stanford University Press, 2003.

MAINWARING, S.; BRINKS, D.; PÉREZ-LIÑAN, A. Classifying political regimes in Latin America, 1945-1999. Studies in Comparative International Development, v. 36, n. 1, p. 37-65, 2001.

MAINWARING, S.; SCULLY, T. R. Party systems in Latin America. In: MAINWARING, S.; SCULLY, T. R. (ed.). Building democratic institutions: party systems in Latin America. Stanford, CA: Stanford University Press, 1995.

MAIR, P. Party system change: approaches and interpretations. Oxford: Clarendon Press, 1997.

MARKOWSKI, R. Party system institutionalization and democratic consolidation: on the idiosyncrasies of the polish case. In: FRENTZEL.ZAGORSKA, J.; WASILEWSKI, J. (ed.). The second generation of democratic elites in Central and Eastern Europe. Warsaw: Institute of Political Studies, Polish Academy of Sciences, 2000.

MAYORGA, R. A. Outsiders and neo-populism: the road to plebiscitary democracy. In: MAINWARING, S.; BEJARANO, A. M.; PIZARRO, E. (ed.). When representation fails: the crisis of democratic representation in the Andes. Stanford: Stanford University Press. No prelo.

MÉNY, Y. Government and politics in Western Europe. Oxford: Oxford University Press, 1990.

MERRILL, S.; GROFMAN, B. A unified theory of voting: directional and proximity spatial models. Cambridge: Cambridge University Press, 1999.

MOLINA, J.; PÉREZ, C. Radical change at the ballot box: causes and consequences of electoral behavior in Venezuela's 2000 elections. Latin American Politics and Society, v. 46, n. 1, p. 103-134, 2004.

MOSER, R. The emergence of political parties in post-Soviet Russia. Ph.D. Thesis, University of Wisconsin, 1995.

Electoral systems and the number of parties in post-communist states. World Politics, v. 51, n. 3, p. 359-384, 1999.

Unexpected outcomes: electoral systems, political parties, and representation in Russia.

Pittsburgh: University of Pittsburgh Press, 2001. 
O'DONNELL, G. Illusions about consolidation. The Journal of Democracy, v. 7, n. 2, p. 34-51, 1996.

OSTIGUY, P. Peronism and anti-peronism: class-cultural cleavages and political identity in Argentina. Ph. D. Thesis, University of California, Berkeley, 1998.

PANEBIANCO, A. Political parties: organization and power. Cambridge: Cambridge University Press, 1988.

PAYNE, M. et al. Democracies in development: politics and reform in Latin America. Washington DC: Inter-American Development Bank and the International Institute for Democracy and Electoral Assistance, 2002.

PEDERSEN, M. N. Changing patterns of electoral volatility in european party systems: explorations in explanation. In: DAALDER, H.; MAIR, P. (ed.). Western european party systems: continuity and change. Beverly Hills: Sage, 1983.

PIZZORNO, A. Interests and parties in pluralism. In: BERGER, S. (ed.). Organizing interests in Western Europe: pluralism, corporatism, and the transformation of politics. New York: Cambridge University Press, 1981.

PRZEWORSKI, A. Institutionalization of voting patterns, or is mobilization the source of decay?. American Political Science Review, v. 69, n. 1, p. 49-67, 1975.

RABINOWITZ, G.; MACDONALD, S. E. A directional theory of issue voting. American Political Science Review, v. 83, n. 1, p. 93-121, 1989.

RABINOWITZ, G.; MACDONALD, S. E.; LISTHAUG, O. Old players in an old game: party strategy in multiparty systems. Comparative Political Studies, v. 24, n. 2, p. 147-185, 1991.

RANDALL, V.; SVÅSAND, L. Party institutionalization in new democracies. Party Politics, v. 8, n. 1, p. 5-29, 2002.

REMMER, K. The political impact of economic crisis in Latin America in the 1980s. American Political Science Review, v. 85, n. 3, p. 777-800, 1991.

ROBERTS, K. M. Neoliberalism and the transformation of populism in Latin America: the peruvian case. World Politics, v. 48, n. 1, p. 82-116, 1995. 
ROBERTS, K. M.; WIBBELS, E. Party systems and electoral volatility in Latin America: a test of economic, institutional, and structural explanations. American Political Science Review, v. 93, n. 3, p. 575-590, 1999.

ROSE, R.; MUNRO, N. Elections and parties in new european democracies. Washington, DC: CQ Press, 2003.

SÁNCHEZ-CUENCA, I. How can governments be accountable if voters vote ideologically?. Center for Advanced Study in the Social Sciences, Institute Juan March, may 2003. Working Paper 191.

SANI, G.; SARTORI, G. Polarization, fragmentation, and competition in western democracies. In: DAALDER, H.; MAIR, P. (ed.). Western european party systems. Beverly Hills: Sage, 1983.

SARTORI, G. Parties and party systems: a framework for analysis. New York: Cambridge University Press, 1976.

Video-power. Government and Opposition, v. 24, n. 1, p. 39-53, 1989.

SCHATTSCHNEIDER, E. E. Party government. New York: Farrar and Reinhart, 1942.

SCHEDLER, A. Under- and over-institutionalization: some ideal typical propositions concerning old and new party systems. University of Notre Dame, Kellogg Institute for International Studies, march 1995. Working Paper \#213.

SCOTT, J. Patron-client politics and political change in Southeast Asia. American Political Science Review, v. 66, n. 1, p. 91-113, 1972.

SCULLY, T. R. Rethinking the center: cleavages, critical junctures, and party evolution in Chile. Stanford: Stanford University Press, 1992.

SIMON, H. A. The science of the artificial. $3^{\text {th }}$ ed. Cambridge: MIT Press, 1996.

SILVEIRA, F. A decisão do voto no Brasil. Porto Alegre: Edipucrs, 1998.

STOCKTON, H. Political parties, party systems, and democracy in East Asia: lessons from Latin America. Comparative Political Studies, v. 34, n. 1, p. 94-119, 2001. 
MAINWARING, S.;TORCAL, M. Teoria e institucionalização dos sistemas partidários...

STOKES, S. Mandates and democracy: neoliberalism by surprise in Latin America. Cambridge: Cambridge University Press, 2001.

Perverse accountability: a formal model of machine politics with evidence from Argentina. American Political Science Review. No prelo.

STONER WEISS, K. The limited reach of Russia's party system: under-institutionalization in dual transitions. Politics and Society, v. 29, n. 3, p. 385-414, 2001.

TANAKA, M. From crisis to collapse of the party systems and dilemmas of democratic representation: Peru and Venezuela. In: MAINWARING, S.; BEJARANO, A. M.; PIZARRO, E. (ed.). When representation fails: the crisis of democratic representation in the Andes. Stanford: Stanford University Press. No prelo.

TAVITS, M. The development of stable party support: electoral dynamics in post-communist Europe. American Journal of Political Science, v. 49, n. 2, p. 283-298, 2005.

TÓKA, G. Political parties and democratic consolidation in East Central Europe. In: DIAMOND, L. et al. (ed.). Consolidating the third wave democracies: themes and perspectives. Baltimore, MD: John Hopkins University Press, 1997.

TORCAL, M.; GUNTHER, R. P.; MONTERO, J. R. Anti-party sentiments in Southern Europe. In: GUNTHER, R. P.; MONTERO, J. R.; LINZ, J. J. (ed.). Political parties: old concepts and new challenges. Oxford: Oxford University Press, 2002.

TORCAL, M.; MAINWARING, S. The political recrafting of social bases of party competition: Chile, 1973-95. The British Journal of Political Science, v. 33, p. 55-84, 2003.

UNDP, United Nations Development Programme. Human Development Report. New York: Oxford University Press, 2003.

VALENZUELA, J. S. The origins and transformations of the chilean party system. In: DEVOTO, F. J.; DI TELLA, T. S. (ed.). Political culture, social movements and democratic transitions in South America in the XXth century. Milan: Feltrinelli, 1997.

VAN COTT, D. L. Party system development and indigenous populations in Latin America: the bolivian case. Party Politics, v. 6, n. 2, p. 155-174, 2000.

WEFFORT, F. O populismo na política brasileira. Rio de Janeiro: Paz e Terra, 1978. 
WESTHOLM, A. Distance versus direction: the illusory defeat of the proximity theory of electoral choice. American Political Science Review, v. 91, n. 4, p. 865-883, 1997.

WEYLAND, K. Neoliberal populism in Latin America and Eastern Europe. Comparative Politics, v. 31, n. 4, p. 379.401, 1999.

WHITE, S.; ROSE, R.; MCALLISTER, I. How Russia votes. Chatham, NJ: Chatham House, 1997.

Em inglês, este texto será publicado em William Crotty e Richard Katz, ed., Handbook of Political Parties (Sage Publications). A Sage autoriza a publicação em Opinião Pública.

Recebido para publicação em março de 2005. Aprovado para publicação em maio de 2005.

Tradução de Pedro Maia Soares. 